\title{
Assimilation, antigemination, and contingent optionality: the phonology of monoconsonantal proclitics in Polish
}

\author{
Bożena Pająk • Eric Baković
}

Received: 1 June 2008 / Accepted: 25 June 2009 / Published online: 14 August 2010

(C) The Author(s) 2010. This article is published with open access at Springerlink.com

\begin{abstract}
Baković (2005) analyzes the avoidance of 'sufficiently similar' adjacent consonants as the interaction of independent antigemination and assimilation processes. We present evidence from the phonology of monoconsonantal proclitics in Polish in support of the primary consequence of this analysis, that any conditions on antigemination or assimilation will also be conditions on 'sufficient similarity' avoidance. These conditions concern the segmental contexts in which geminates are disallowed in Polish and the variability of one of the assimilation processes involved. The analysis is further corroborated by the coincidence of two changes in progress: as the rate of variable assimilation has gone down, so has the rate of 'sufficient similarity' avoidance.
\end{abstract}

Keywords Antigemination · Epenthesis · Assimilation · Variation · Change $\cdot$ Polish

\section{Introduction}

In this article we present novel evidence from Polish in support of the analysis of 'sufficiently similar' adjacent consonant avoidance developed by Baković (2005). Baković attributes the 'sufficient similarity' of avoided sequences of adjacent consonants to the interaction of an independent antigemination process (here, epenthesis) with consonantal assimilation processes, such that epenthesis applies between adjacent nonidentical consonants if and only if assimilation between them would otherwise be expected to lead to the creation of a geminate.

B. Pająk $(\bowtie) \cdot$ E. Baković Linguistics Department, University of California San Diego, 9500 Gilman Dr. \#0108, La Jolla, CA, 92093-0108, USA

e-mail: bpajak@ling.ucsd.edu

E. Baković

e-mail: bakovic@ling.ucsd.edu 
The essence of this analysis can be conveyed most straightforwardly with the wellknown set of surface alternations of the past tense suffix /d/ in English (Baković 2005: $284 f f)$. This suffix is realized as voiceless [ $\mathrm{t}$ ] after stem-final voiceless consonants (e.g. /bi:p+d/ $\rightarrow$ [bi:pt] 'beeped') and is separated by a schwa from a stem-final, 'sufficiently similar' /t/ or /d/ (e.g. /si:t $+\mathrm{d} / \rightarrow$ [si:təd] 'seated'). The fact that schwa is epenthesized after identical /d/ as well as after nonidentical/t/, Baković (2005) argues, is due to an interaction between strict antigemination-driven epenthesis (that is, epenthesis to avoid adjacent, strictly identical consonants) and the independentlymotivated process of voicing assimilation. Because assimilation would otherwise be expected to result in the [t] allomorph of the past tense suffix after stem-final $/ t /$, the best way to avoid both a geminate $[\mathrm{t}+\mathrm{t}]$ and the unassimilated sequence $[\mathrm{t}+\mathrm{d}]$ is to epenthesize a schwa: $[\mathrm{t}+$ əd].

The avoidance of 'sufficiently similar' adjacent consonants is thus an epiphenomenon of the interaction between assimilation and strict antigemination in Baković's analysis. The general prediction, then, is that similar-but-nonidentical adjacent consonant avoidance will be subject to whatever independent conditions there may be on the independent antigemination and assimilation processes. We present here three significant pieces of evidence in support of this prediction from the phonological behavior of monoconsonantal proclitics in Polish.

The first piece of evidence, discussed in Sect. 2, concerns the fact that geminates in Polish are only systematically avoided via epenthesis word-initially before an-

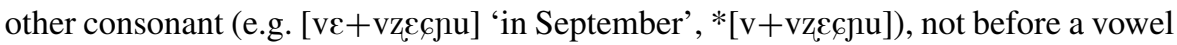
(e.g. [v+vozit6] 'to carry in'). This segmental context, which we define as 'nonvowel-adjacent', is thus a condition on antigemination-driven epenthesis in Polish. As predicted by Baković's analysis, nonidentical consonants that are otherwise expected to become identical by voicing assimilation are also specifically avoided via epenthesis in the same non-vowel-adjacent contexts (e.g. [ve+ftorck] 'on Tuesday', $*[\mathrm{f}+\mathrm{ft}$ วrek $])$.

The second piece of evidence, discussed in Sect. 3, concerns the fact that there is a variable process of consonantal assimilation in Polish, a process we call 'coronal place assimilation' or CPA (e.g. [z+zabõ] [z+zabõ] 'with a frog'). As expected based on its interaction with voicing assimilation, epenthesis applies in just those contexts where application of CPA would otherwise lead to a non-vowel-adjacent geminate (e.g. [ze+zviru] 'from gravel', *[z+zviru]). But because CPA is variable, we expect epenthesis to also be optional in such contexts—and, as discussed in Sect. 4, this is in fact what we find (e.g. [z+zviru] $\sim$ [ze+zviru $]$ ).

The third piece of evidence involves indications of changes in progress that can be gleaned from the distributions of variation in both CPA and epenthesis in Polish. If the variability of epenthesis is indeed due to the variability of CPA, we would expect that any diachronic change in the rate of CPA would lead to a change in the rate of epenthesis, in the same direction. The data we report in Sect. 4 support this conclusion: there is a gradual decline in the rates of both CPA and epenthesis (in those contexts where the latter is optional, of course). 


\section{Voicing assimilation and epenthesis}

In this section we discuss the interaction between voicing assimilation and epenthesis as they apply to the Polish monoconsonantal proclitics /v/ and /z/. ${ }^{1}$ The data and proposed analysis are presented in Sect. 2.1; the analysis is in essential respects identical to that of the English past tense in Bakovic (2005) except that the segmental context of the constraint against geminates must be restricted to 'non-vowel-adjacent' positions in Polish. In Sect. 2.2 we provide independent support for the contextual restriction on this constraint. Finally, in Sect. 2.3 we show how the purely phonological conditions on the epenthesis process discussed in Sect. 2.1 are completely independent from the morphophonological conditions on what is often assumed to be the process of "yer" vocalization in Polish proclitics.

\subsection{Data and analysis}

Sequences of obstruents in Polish must agree in voicing, both word-internally and across clitic or word boundaries (e.g. Bethin 1992). This is achieved by regressive voicing assimilation. That is, in a $\mathrm{C}_{1} \mathrm{C}_{2}$ cluster of obstruents, the voicing of $\mathrm{C}_{1}$ is determined by that of $\mathrm{C}_{2} \cdot{ }^{2}$ Therefore, the proclitics / $/$ / and /z/ always agree in voicing with a following obstruent, as shown in (1).

\section{(1) Regressive voicing assimilation of monoconsonantal proclitics}

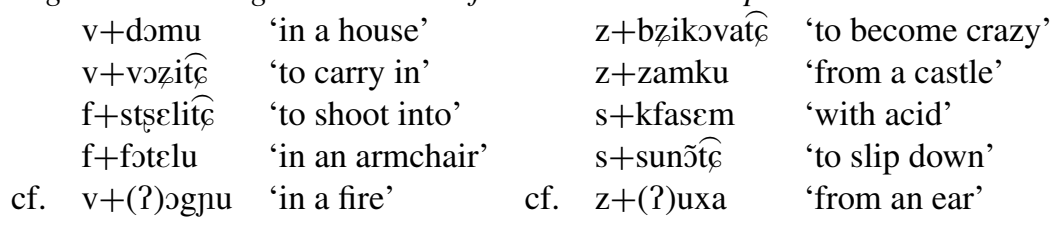

For the purposes of our analysis in Optimality Theory (OT; Prince and Smolensky $1993 / 2004$ ), we assume that voicing assimilation is triggered by the markedness constraint AGREE[voi], which penalizes adjacent obstruents that disagree in $[ \pm$ voice] (Lombardi 1999). Accordingly, obstruents that change their voicing from input to output in order to satisfy AGREE[voi] violate the faithfulness constraint IDENT[voi] (McCarthy and Prince 1995). Informal definitions of these constraints are provided in (2).

\footnotetext{
${ }^{1}$ The proclitics / $/ \mathrm{and} / \mathrm{z} /$ function as either prefixes or prepositions, and most commonly have the meanings "in" and "with"/"from", respectively. When used with verbs, the proclitics can also indicate perfective aspect.

${ }^{2}$ Polish also has a very limited process of progressive voicing assimilation. It applies to two voiced fricatives only (/zl and /v/), which are devoiced following a voiceless obstruent (e.g. Bethin 1992). The status of these two fricatives is special: $/ z /$ is in these cases etymologically derived from, and alternates with, /r/, and /v/ plausibly comes from the underlying sonorant /w/ (e.g. Bethin 1992; Gussmann 2007). / $\mathrm{z} /$ and $/ \mathrm{v} /$ are thus often argued to behave exceptionally with respect to voicing assimilation because of their status as sonorants, rather than because of the application of a separate process of progressive voicing assimilation (e.g. Bethin 1992; Gussmann 2007).
} 
(2) Informal definitions of constraints responsible for voicing assimilation

AGREE[voi] Adjacent obstruents must have the same value for voicing.

IDENT[voi] Input and output correspondents must have the same value for voicing.

Voicing assimilation is enforced by ranking AGREE[voi] above IDENT[voi], as shown in the tableau in (3i). The candidate that undergoes assimilation (b) is optimal since it satisfies the higher-ranked constraint AGREE[voi]. In (3ii), on the other hand, the faithful candidate (a) wins because it satisfies both AGREE[voi] and IDENT[voi]. ${ }^{3}$ Other faithfulness constraints, such as the anti-consonant-deletion constraint $\operatorname{MAX}(\mathrm{C})$ and the anti-vowel-epenthesis constraint $\operatorname{DEP}(\mathrm{V})$, must also outrank IDENT[voi] to prevent satisfaction of AGREE[voi] via deletion or epenthesis.

(3) Regressive voicing assimilation

i. Devoicing

\begin{tabular}{|c|c|c|}
\hline /zpa/ & AGREE[voi] & IDENT[voi] \\
\hline a. $\quad$ zpa & $* !$ & \\
\hline b. $\rightarrow$ spa & & $*$ \\
\hline
\end{tabular}

ii. Faithfulness

\begin{tabular}{|l||c|c|}
\hline /zba/ & AGREE[voi] & IDENT[voi] \\
\hline a. $\rightarrow$ zba & & \\
\hline b. sba & $* !$ & $*$ \\
\hline
\end{tabular}

In contexts such as those illustrated in (4), the proclitics /v/ and /z/ surface with an epenthetic vowel separating the proclitic from the following word.

(4) Vowel epenthesis before $\{v / f\} C$ or $\{z / s\} C$

a. Clitic /v/

$$
\begin{aligned}
& / v+v g w \tilde{\varepsilon} b^{j} \varepsilon \jmath u / \rightarrow v \varepsilon+v g w \tilde{\varepsilon} b^{j} \varepsilon \jmath u \text { 'in a cavity' cf. }{ }^{*} v+v g w \tilde{\varepsilon} b^{j} \varepsilon \jmath u
\end{aligned}
$$

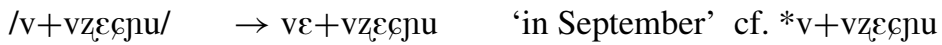

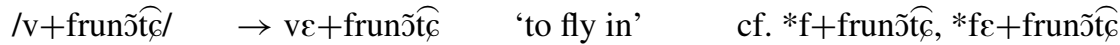

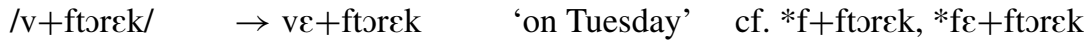

b. Clitic /z/

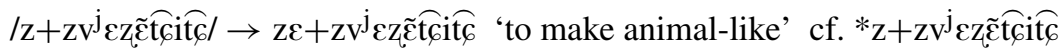

$$
\begin{aligned}
& \mathrm{z}+\mathrm{znak}^{\mathrm{j}} \mathrm{\varepsilon m} / \rightarrow \mathrm{z}^{\mathrm{m}}+\mathrm{znak}^{\mathrm{j}} \mathrm{\varepsilon m} \text { 'with a sign' } \quad \text { cf. }{ }^{*} \mathrm{z}+\mathrm{znak}^{\mathrm{j}} \varepsilon \mathrm{m}
\end{aligned}
$$

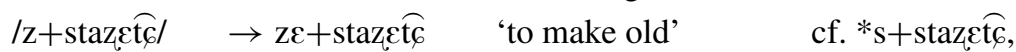

$$
\begin{aligned}
& * s \varepsilon+\text { staze } \overparen{t} 6
\end{aligned}
$$

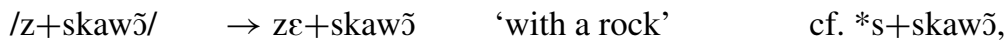

$$
\begin{aligned}
& \text { *sc+skaw ̃ }
\end{aligned}
$$

It has been observed by many authors (e.g. Steele 1973; Laskowski 1975; Rubach 1977, 1985; Bethin 1992; Gussmann 2007) that the vowel insertion in (4) is phono-

\footnotetext{
${ }^{3}$ The regressive direction of voicing assimilation can be assured by assuming the existence of a positional faithfulness constraint, whether prosody-based (Beckman 1998; Lombardi 1999) or string-based (Rubach 2008), which is violated by changes to the final, prevocalic obstruent of a cluster.
} 
logically conditioned. Epenthesis applies whenever a monoconsonantal proclitic attaches to a word that begins with a 'sufficiently similar' consonant (i.e. [v] or [f] for the clitic /v/, and [z] or [s] for the clitic /z/) followed by another consonant.

Epenthesis does not apply to split up other word-initial complex consonant clusters, as shown in (5a); on the contrary, Polish allows very complex onsets. Nor does epenthesis apply when the clitic attaches to a word that simply begins with either [v] or [f], or [z] or [s], because the examples shown in (5b) are perfectly well-formed. ${ }^{4}$ Epenthesis only takes place when the clitics attach to a word that begins with a 'sufficiently similar' segment in a consonant cluster. ${ }^{5}$

\section{(5) No epenthesis}

a. In other complex consonant clusters

\begin{tabular}{|c|c|c|}
\hline $\mathrm{v}+$ drz̨eju & 'in a tremble' & cf. $*_{v \varepsilon}+$ drzeju \\
\hline 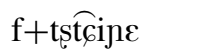 & 'in a cane' & cf. $*_{\mathrm{v} \varepsilon}+\mathrm{t}$ tstcing \\
\hline $\mathrm{z}+\mathrm{bzd} \tilde{\varepsilon} \mathrm{k}^{\mathrm{j}} \varepsilon \mathrm{m}$ & 'with a plunk' & cf. ${ }^{*} \mathrm{z} \varepsilon+\mathrm{bzd} \tilde{\varepsilon} \mathrm{k}^{\mathrm{j}} \varepsilon \mathrm{r}$ \\
\hline s+pștşow & 'with a bee' & cf. $*_{\mathrm{z} \varepsilon}+$ pștşow \\
\hline \multicolumn{3}{|c|}{ Before $\{v / f\} V$ or $\{z / s\} V$} \\
\hline $\mathrm{v}+$ vanje & 'in a bathtub' & cf. $*_{\mathrm{v} \varepsilon}+$ vanje \\
\hline $\mathrm{f}+$ fabritss & 'in a factory' & cf. $* v \varepsilon+$ fabrits $\varepsilon$ \\
\hline $\mathrm{z}+\mathrm{zamku}$ & 'from a castle' & cf. $*$ z $\varepsilon+$ zamku \\
\hline $\mathrm{s}+\mathrm{s} \varepsilon \mathrm{r \varepsilon m}$ & 'with cheese' & cf. $*_{\mathrm{z} \varepsilon}+\mathrm{scr \varepsilon m}$ \\
\hline
\end{tabular}

\footnotetext{
${ }^{4}$ Rubach (1985) notes that in the dialects of southern and western Poland, epenthetic forms are possible in this context; that is, before $\{\mathrm{v} / \mathrm{f}\} \mathrm{V}$ for the clitic $/ \mathrm{v} /$, and before $\{\mathrm{z} / \mathrm{s}\} \mathrm{V}$ for the clitic $/ \mathrm{z} /$. We will not be concerned with these dialectal variants in this paper.

${ }^{5}$ There are a few more cases in which epenthesis seems to variably apply to the clitics /v/ and /z/. We believe that there are different reasons behind each of them. (1) Epenthesis applies to the clitic $/ z /$ when the stem begins with either [vz]C or [fs]C, e.g. [ze+vzglẽdu] 'in regard of' or [ze+fspompensm] 'with a memory.' This may be due to the fact that [v] or [f] are often deleted (or at least weakened) in onset clusters (Dunaj 1985), yielding the same context as in (4b). Note that epenthesis does not apply in cases when the stem begins with [vz]V or [fs]V, e.g. [z+vzajemnoctcõ] 'with reciprocity' or [s+fsufkõ] 'with a pin,' nor when the intervening consonant is not [v] or [f], e.g. [z+bzdurõ] 'with nonsense' or-for an analogous case with the clitic $/ \mathrm{v} /-\left[\mathrm{v}+\mathrm{zvr} \widehat{C}_{6} \varepsilon\right]$ 'in a turn.' (2) A reviewer points out that-contrary to what is stated in the previous sentence-there are cases of epenthesis in the clitic /z/ when the stem begins with either [vz]V or [fs]V. We believe that this is analogous to the dialectal differences mentioned in footnote 4, since epenthesis is in these cases possible only for some speakers. (3) A reviewer also

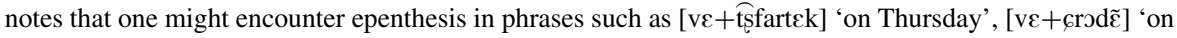
Wednesday', or [ze+lvova] 'from Lvov', where the stem begins with different complex clusters. However, epenthesis here is again only acceptable by some speakers. In addition, it only seems to occur in a handful of high frequency words, instead of applying productively in the relevant phonological contexts (e.g.

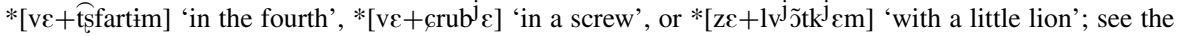
examples in the Polish dictionary by Markowski (ed.) 1999). While more research is certainly needed to investigate these cases in detail, for now we feel justified in assuming that they are in fact distinct from the productive, phonologically-motivated pattern under discussion. The reasons why some speakers might apply epenthesis in these seemingly unmotivated cases include dialectal differences, overgeneralization of epenthesis to all stridents or complex clusters, or influence from historical forms in which epenthesis was highly predominant.
} 
Previous analyses of the pattern of epenthesis in (4) and the lack thereof in (5) rely on some form of a rule for vowel epenthesis, such as the rule provided in (6).

\section{(6) Rule for vowel epenthesis in proclitics (adapted from Rubach 1977: 118) ${ }^{6}$ \\ $\emptyset \rightarrow \varepsilon / \mathrm{HC}_{1}+\ldots \mathrm{C}_{2} \mathrm{C}$ \\ where $\mathrm{C}_{1}$ and $\mathrm{C}_{2}$ are 'sufficiently similar' (= identical ignoring [ \pm voice $]$ )}

Note that this rule completely stipulates the meaning of 'sufficient similarity' between consonants, which in this context is intended to mean 'identical except for the feature $[ \pm$ voice]'. No motivation is offered for ignoring this particular feature as opposed to any other. ${ }^{7}$ An analogous problem was noticed by Baković (2005) in defining the rule of vowel epenthesis in English past tense forms like /si:t+d/ 'seated' and $/ \mathrm{s}: \mathrm{id}+\mathrm{d} /$ 'ceded'. Baković proposes an analysis of this type of alternation that does not require any stipulation of 'sufficient similarity'. He argues that epenthesis in English past tense forms is actually triggered in order to avoid adjacent identical consonants, not just 'sufficiently similar' ones. The analysis relies on the fact that voicing assimilation is an independently motivated process in English in this context: if voicing assimilation were to apply in cases like $/ \mathrm{t}+\mathrm{d} /$ or $/ \mathrm{d}+\mathrm{d} /$, the result would be a sequence of completely identical adjacent consonants: [tt] and [dd]. That is, epenthesis applies whenever the result would otherwise be a sequence of adjacent identical consonants - a geminate-due to the independently motivated process of voicing assimilation.

Vowel epenthesis in Polish proclitics can be straightforwardly accounted for using Baković's analytic framework. If voicing assimilation were to apply to the input forms shown in (7) below, the result would be a word-initial sequence of completely identical adjacent consonants followed by another consonant. Therefore, even though Polish allows word-initial geminates (as shown in (5b) above), it disallows initial geminates followed by a consonant and repairs prospective tokens of such sequences by epenthesizing a vowel between the two halves of the potential geminate.

\footnotetext{
${ }^{6}$ Rubach's exact formulation of the rule is the following:

$\varnothing \rightarrow \varepsilon / \#[+$ cons, $\alpha \mathrm{F}] \ldots[+$ cons, $\alpha \mathrm{F}][+$ cons $]$, where $\mathrm{F}=$ features except [voiced $]$.

${ }^{7}$ A reviewer points out that this special status of voicing with respect to 'sufficient similarity' is not unique to Polish. In Muna, homorganic consonants that are too similar do not co-occur in a root; homorganic consonants that differ only in terms of [ \pm voice $]$ are the most severely restricted and do not co-occur at all (see Van den Berg 1989 and Coetzee and Pater 2008a, 2008b). This point about long-distance similarity avoidance is well-taken, but in our opinion does not materially affect the argument made by Baković (2005) that cases of 'sufficiently similar' adjacent consonant avoidance suspiciously appear to always co-occur with assimilation processes that can be used to explain the content of 'sufficient similarity'. Moreover, there is an additional process of coronal place assimilation (CPA) in Polish that is variable (see Sect. 3), and this process appears to play a crucial role in defining 'sufficient similarity' for the purposes of explaining the variability of epenthesis observed in a set of contexts precisely delimited by the interaction with CPA (see Sect. 4). This would be yet another accidental coincidence if 'sufficient similarity' were to be defined by some means other than the interaction between antigemination and assimilation, as this reviewer appears to suggest.
} 
(7) Vowel epenthesis in proclitics, following Baković (2005)
a. Clitic/v/

\begin{tabular}{|c|c|c|}
\hline /v+vzeçıu/ & $\nRightarrow *_{\mathrm{v}}+\mathrm{vz} \varepsilon \varepsilon_{6} \mathrm{u}$ & 'in September \\
\hline$/ \mathrm{v}+$ frunõt $\overparen{\text { Cl }}$ & 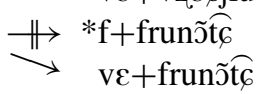 & 'to fly in' \\
\hline
\end{tabular}
b. Clitic /z/

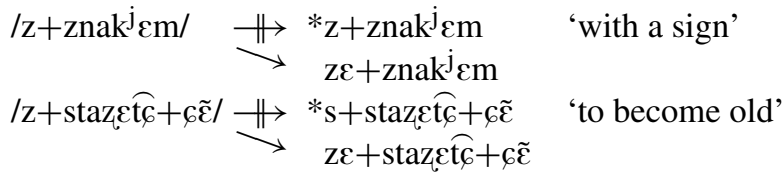

Analyses of the type sketched above are problematic for a rule-based account, as discussed at length by Baković (2005, 2007), but can be easily carried out in OT. The following constraints interact to yield the desired result: $\operatorname{DEP}(\mathrm{V})$ (which penalizes vowel epenthesis), AGREE[voi] (which penalizes obstruent clusters that disagree in $[ \pm$ voice $])$, and another markedness constraint that penalizes adjacent identical consonants (geminates) that are both word-initial and followed by another consonant. We propose to call this constraint NoGEM/NVA, where NVA stands for 'nonvowel-adjacent'. This constraint is based on the NOGEM constraint proposed by Rose (2000) and also employed by Baković (2005), but it targets geminates that occur in a specific segmental context: NoGEM/NVA penalizes geminates that are not adjacent to any vowel. (See Sect. 2.2 for further discussion and motivation of this constraint.)

Following Baković (2005), we assume that NOGEM and any contextual constraint based on it penalizes any geminate (in the relevant context that may be defined by the constraint) regardless of its exact structural representation. That is, the definition of NoGEM is assumed to encompass both basic ('true') and derived ('fake') geminates.

Informal definitions of the three crucial constraints are given in (8).

\section{(8) Informal definition of the constraints responsible for vowel epenthesis \\ AGREE[voi] Adjacent obstruents must have the same value for voicing \\ NoGEM/NVA Geminates not adjacent to any vowel are not allowed \\ $\operatorname{DEP}(\mathrm{V}) \quad$ No vowel epenthesis}

As already discussed, the candidate with epenthesis surfaces in order to avoid an initial geminate followed by another consonant that would otherwise arise due to the operation of voicing assimilation, which is independently active in the language (e.g. $/ \mathrm{v}+\mathrm{vz} \varepsilon / \rightarrow[\mathrm{v} \varepsilon+\mathrm{vz} \varepsilon], *[\mathrm{v}+\mathrm{vz} \varepsilon]$ and $/ \mathrm{v}+\mathrm{f} s \varepsilon / \rightarrow[\mathrm{v} \varepsilon+\mathrm{f} s \varepsilon], *[\mathrm{f}+\mathrm{f} s \varepsilon])$. Therefore, $\operatorname{DEP}(\mathrm{V})$ is violated in order to jointly satisfy the higher-ranked constraints NoGEM/NVA and AGREE[voi], and DEP(V) must thus be dominated by both NoGEM/ NVA and AgreE[voi]. The tableaux in (9) illustrate how this ranking yields the correct results. In both cases, the candidates assimilated in voicing (a) are eliminated by NoGEM/NVA, whereas the candidates that satisfy NoGEM/NVA by virtue of disagreeing in voicing (b) are eliminated by AGREE[voi]. The candidates with epenthesis (c), which violate DEP(V), surface as optimal in this situation ensuring that neither 
NOGEM/NVA nor AGREE[voi] are violated. ${ }^{8}$ (Note that no ranking between the constraints NoGEM/NVA and AGREE[voi] can be justified.)

(9) Vowel epenthesis

\begin{tabular}{|c|c|c|c|}
\hline$/ v+v z \varepsilon /$ & NOGEM/NVA & AGREE[Voi] & $\operatorname{DEP}(\mathrm{V})$ \\
\hline$[\mathrm{v}+\mathrm{vZq \varepsilon}]$ & $* !$ & & \\
\hline$[\mathrm{f}+\mathrm{vz} \varepsilon]$ & I & $* !$ & \\
\hline c. $\rightarrow[\mathrm{v} \varepsilon+\mathrm{vz} \varepsilon]$ & 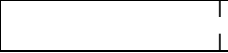 & & $*$ \\
\hline
\end{tabular}

\begin{tabular}{|c|c|c|c|}
\hline$/ \mathrm{v}+\mathrm{f} s \mathrm{~g} /$ & NOGEM/NVA & AGREE[voi] & $\operatorname{DEP}(\mathrm{V})$ \\
\hline$[\mathrm{f}+\mathrm{f} \operatorname{s} \varepsilon]$ & $* !$ & & \\
\hline$[\mathrm{v}+\mathrm{f} s \varepsilon]$ & & $* !$ & \\
\hline c. $\rightarrow[\mathrm{v} \varepsilon+\mathrm{f} s \varepsilon]$ & & & $*$ \\
\hline
\end{tabular}

One more ranking is essential for a complete analysis of the interaction of voicing assimilation and epenthesis: the faithfulness constraint IDENT[voi] must be ranked below $\operatorname{DEP}(\mathrm{V})$ so that the candidate with epenthesis is eliminated in contexts where NoGEM/NVA is not at stake and voicing assimilation applies instead. This ranking was in fact already mentioned in the discussion preceding the tableaux in (3) and is more completely illustrated in the tableaux in (10).

\section{(10) No epenthesis}

\begin{tabular}{|c|c|c|c|}
\hline$/ \mathrm{v}+\mathrm{bze} /$ & NOGEM/NVA AGREE[voi & $\operatorname{DEP}(\mathrm{V})$ & IDENT[Voi] \\
\hline a. $\rightarrow[\mathrm{v}+\mathrm{bzz} \varepsilon]$ & 1 & & \\
\hline$[\mathrm{f}+\mathrm{bz} \varepsilon]$ & $* !$ & & $*$ \\
\hline c. $[\mathrm{v} \varepsilon+\mathrm{bz} \varepsilon]$ & 1 & $* !$ & \\
\hline
\end{tabular}

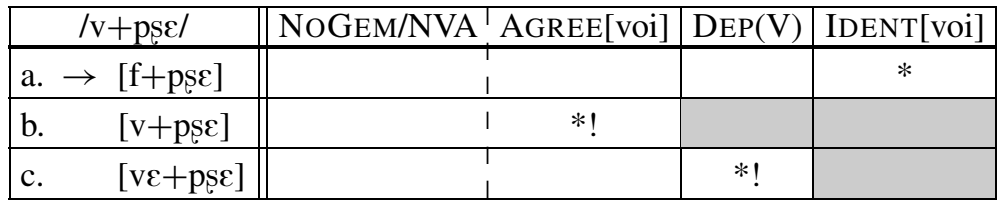

The motivation for the ranking of DEP(V) above IDENT[voi] comes from the second tableau only, where the clitic / $/$ / changes its underlying voicing value in order to satisfy AGREE[voi] (a). In the first tableau, the candidate in which the relevant consonants agree in voicing (a) is also the faithful candidate, and thus does not violate any of the constraints in the analysis.

\footnotetext{
${ }^{8}$ Note that NoGEM/NVA could in principle also be satisfied by epenthesis between the geminate and the following consonant in the cluster (e.g. *[vveze]). We assume that such candidates are eliminated by another contextual constraint on geminates, NOGEM/1VA, which penalizes geminates adjacent to only one vowel; see Sect. 2.2 for further discussion. A reviewer points out that if a yer-deletion-blocking analysis (discussed in Sect. 2.3) is employed instead, the issue of other positions for epenthesis disappears, as $\operatorname{DEP}(\mathrm{V})$ is then probably undominated in Polish.
} 
To conclude, the ranking of constraints required for this analysis is the following: NoGEM/NVA, AGREE[voi] $\gg \operatorname{DEP}(V) \gg$ IDENT[voi]. This ranking entails that epenthesis will apply to avoid both geminates and nonidentical but 'sufficiently similar' adjacent consonants in the same segmental context; namely, in the non-voweladjacent context potentially created by a monoconsonantal proclitic followed by a relevant word-initial consonant cluster.

\subsection{Contextual constraints on geminates}

In Sect. 2.1 we proposed to use the constraint NOGEM/NVA which targets geminates in non-vowel-adjacent contexts. In this subsection we briefly discuss the motivation for positing contextual constraints on geminates, and we show how these constraints are central to an account of the overall distribution of geminates in Polish (for a complete analysis see Pająk 2009b).

Previous work has shown that segmental context is an important property that often needs to be taken into account in the phonological analysis of geminates (see e.g. Muller 1999; McCrary 2004). Adjacency to vowels appears to be especially important: typological evidence shows that geminates are most common intervocalically, and most rare when not adjacent to any vowel (Thurgood 1993; Muller 2001; plus an informal survey of 40 languages with geminates). This typological fact correlates with perceptual evidence: intervocalic singleton-geminate contrasts are the most perceptible, and non-vowel-adjacent singleton-geminate contrasts are the least perceptible (Pająk 2009a; see also McCrary 2004; Dmitrieva 2009).

Vowel adjacency thus constitutes an important property that helps define common and uncommon geminate contexts. This property can be incorporated into phonological theory by re-defining the monolithic constraint on geminates, NoGEM, as a family of constraints that target geminates in different contexts. This is analogous to the proposal of splitting NOGEM into a family of constraints targeting particular segmental types of geminates (NoGEMGlide, NoGEMOBS, etc.; Podesva 2002; Kawahara 2005). Informal definitions of the proposed contextual constraints on geminates are shown in (11).

NoGEM/V_V Geminates flanked by vowels are not allowed ('no intervocalic geminates').

NoGEM/1VA Geminates adjacent to exactly one vowel are not allowed ('no single vowel-adjacent geminates').

NoGEM/NVA Geminates not adjacent to any vowel are not allowed ('no nonvowel-adjacent geminates').

These contextual constraints may need to be more specific than defined here, incorporating information about word position or combining with segmental-type constraints (e.g. NoGEMOBS/NVA). For present purposes, we leave such considerations as open questions.

A universal ranking of these contextual constraints can be established based on the typological and perceptual facts noted earlier, as shown in (12). The constraint against 
non-vowel-adjacent geminates is ranked the highest, while the constraint against intervocalic geminates is ranked the lowest. ${ }^{9}$

(12) Universal ranking of contextual constraints on geminates

\section{NoGEM/NVA $\gg$ NoGEM/1VA $\gg$ NoGEM/V_V}

The proposed contextual constraints in (11) and their ranking in (12) are central to the account of the overall distribution of geminates in Polish. There are examples in Polish of both 'true' geminates, which are underlyingly long (mostly borrowings from other languages), and of 'fake' geminates, which are derived via certain morphological processes (for discussion of geminates in Polish see e.g. Zajda 1977; Rubach 1986; Rubach and Booij 1990; Sawicka 1995; Thurgood 2002). Geminates in Polish behave fairly typically when compared to other languages in that they are mainly found intervocalically, as shown in (13).

\section{(13) Intervocalic geminate consonants}

$\begin{array}{llll}\text { fontanna } & \text { 'fountain' } & \text { ballada } & \text { 'ballad' } \\ \text { lekko } & \text { 'lightly' } & \text { bezzasadni } & \text { 'unreasonable' }\end{array}$

Whenever there is the potential to create a non-intervocalic geminate in Polish (e.g. via affixation), one of the consonants of the would-be geminate is deleted (Rubach and Booij 1990), as shown in (14). We refer to this deletion process here as degemination.

(14) Degemination in non-intervocalic contexts

\begin{tabular}{|c|c|c|c|c|c|}
\hline $\mathrm{p}^{\mathrm{j}} \tilde{\varepsilon} \mathrm{kn}-\mathrm{\jmath}$ & 'beauty' & $+\mathrm{ni}$ & $\mathrm{p}^{\mathrm{j}} \tilde{\varepsilon} \mathrm{k}-n \dot{\mathrm{f}}$ & 'beautiful' & $* p^{j} \tilde{\varepsilon} k n-n \dot{\imath}$ \\
\hline & 'Seville' & + ski & scvil-ski & 'Sevillian' & $*_{\text {sevill-ski }}$ \\
\hline fontann- $\dot{t}$ & 'fountains' & (Nom.) but & fontan & 'fountains' (Gen.) & *fontann \\
\hline
\end{tabular}

Degemination also optionally applies in the same segmental contexts at clitic and word boundaries (Sawicka 1995: 153), as shown in (15).

$$
\begin{array}{ll}
\text { Optional degemination } & \\
\text { bes+stronni } \sim \text { be+stronni } & \text { 'impartial' } \\
\text { roz+zwo6t6it6 } \sim \text { ro+zwo6t6itc } & \text { 'to enrage' } \\
\text { kask\#\#kazdi } \sim \text { kas\#\#kazdi } & \text { 'every helmet' }
\end{array}
$$

The only exception concerns monoconsonantal proclitics, which can create single vowel-adjacent geminates by attaching to a word that begins with a 'sufficiently sim-

\footnotetext{
${ }^{9}$ There are languages which seem to allow word-initial geminates but not medial intervocalic ones, such as Pattani Malay, Iban, Sa'ban (Austronesian), or Nhaheun (Austro-Asiatic) (Blust 1995, 2001, 2007; Muller 2001). Independent diachronic factors are responsible for the apparent exceptionality of these cases; see Pająk 2009b for discussion.
} 
ilar' consonant followed by a vowel, as illustrated in (16). ${ }^{10}$ We assume that degemination is not possible in such cases because it would lead to the loss of the entire proclitic. (Casali (1997: 506ff.) discusses similar cases in which the result of an otherwise expected vowel deletion process is blocked just in case an entire morpheme would be sacrificed.)

(16) Single vowel-adjacent (initial) geminates

\begin{tabular}{|c|c|c|}
\hline$v+$ vozit 6 & 'to carry in' & $* \emptyset+$ vozit 6 \\
\hline $\mathrm{f}+\mathrm{f} \partial t \varepsilon l u$ & 'in an armchair' & $* \varnothing+$ fotclu \\
\hline $\mathrm{z}+\mathrm{z} \tilde{\varepsilon} \mathrm{b} \varepsilon \mathrm{m}$ & 'with a tooth' & $* \emptyset+\mathrm{z} \tilde{\varepsilon} \mathrm{b} \varepsilon \mathrm{m}$ \\
\hline$s+\operatorname{sun} \tilde{t} \widehat{\epsilon}$ & 'to slip down' & $* \varnothing+$ sul \\
\hline
\end{tabular}

However, as discussed in Sect. 2.1, even though single vowel-adjacent geminates are tolerated word-initially, non-vowel-adjacent geminates are strictly forbidden. Whenever a monoconsonantal proclitic is attached to a word that begins with a 'sufficiently similar' segment followed by a consonant, a vowel is epenthesized immediately after the clitic, as shown in (17). ${ }^{11}$

(17) Avoidance of non-vowel-adjacent geminates (repeated from (7))

a. Clitic /v/

\begin{tabular}{|c|c|c|}
\hline /v+vzeçul & $\| *_{v}+\mathrm{vz \varepsilon} \varepsilon \rho u$ & 'in September' \\
\hline$/ v+$ frunõt & 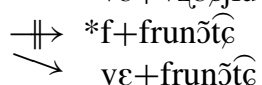 & 'to fly in' \\
\hline
\end{tabular}

b. Clitic /z/

$$
\begin{aligned}
& \mathrm{z}+\mathrm{znak}^{\mathrm{j}} \mathrm{\varepsilon m} / \underset{{ }^{2}}{\longrightarrow}{ }_{\mathrm{z}}+\mathrm{znak}^{\mathrm{j}} \mathrm{\varepsilon m} \quad \text { 'with a sign' }
\end{aligned}
$$

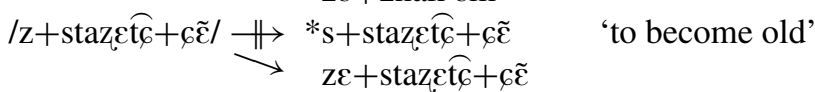

The behavior of geminates in Polish thus constitutes a classic case of a conspiracy (Kisseberth 1970; Pater 1999). Only intervocalic geminates seem to be freely allowed in the language. Whenever a geminate would be expected to surface in a nonintervocalic context due to morphological concatenation, degemination takes place instead. However, degemination is blocked whenever it would cause deletion of an entire clitic. In these cases word-initial geminates are either tolerated (when followed

\footnotetext{
${ }^{10}$ Polish also has four monomorphemic words with initial geminates-three of them affricates-plus a

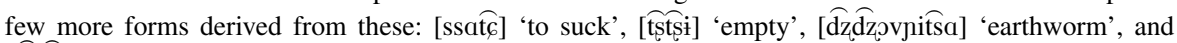
[dz̧dzisti] 'rainy'. Due to this limited number of examples, we conclude that they are simply exceptions to a ban on monomorphemic word-initial geminates in Polish. This conclusion receives some support from the fact that-in contrast to medial affricate geminates, which are typically pronounced with long closure and a single release-initial affricate geminates are always pronounced as two successive closure+release phases (Dunaj 1985), which casts some doubt on whether they are in fact geminates.

${ }^{11}$ There is one exception: epenthesis does not apply to the word [s+stõpiţ] 'to descend' (plus other paradigmatic variants), a word that has fallen out of use and is used almost exclusively in rote religious contexts (as in 'God descended on earth').
} 
by a vowel, or single vowel-adjacent) or repaired by vowel epenthesis (when followed by a consonant, or non-vowel adjacent).

This pattern can be straightforwardly accounted for with the proposed contextual constraints on geminates. Intervocalic geminates are allowed due to the low ranking of NoGEM/V_V. Single vowel-adjacent geminates are disallowed because of the higher-ranking constraint NoGEM/1VA, which enforces degemination. The only cases of non-intervocalic geminates which surface in the language, as in (16), are due to REALIZEMORPHEME (e.g. Kurisu 2001), which requires that an input morpheme be realized in the output. Finally, non-vowel-adjacent geminates do not surface due to the undominated constraint NOGEM/NVA. REALIZEMORPHEME ensures that potential non-vowel-adjacent geminates, as in (17), are repaired by vowel epenthesis instead of degemination. For more discussion and a complete OT analysis of this pattern, see Pająk (2009b).

\subsection{A sidenote: yers}

There are other contexts in which the proclitics /v/ and /z/ surface with what appears to be an epenthetic vowel, as shown in the perfective form of the prefixed verbs in (18a) below. It should be noted, however, that the context responsible for the appearance of a vowel in (18a) is in fact completely independent from the phonological context that triggers the vowel epenthesis that is of primary interest in this paper. The common assumption is that the underlined vowels in (18a) are 'yers', abstract vowels that surface (are 'vocalized') whenever there is an unvocalized underlying yer in the following syllable, and that otherwise delete (see e.g. Gussmann 1980). The imperfective verb forms on the left in (18a) show that the relevant verb stem contains a yer vowel; in the perfective forms to the right, the stem yer remains unvocalized, which in turn triggers vocalization of the clitic-final yer. The proclitic vowel is assumed to be non-epenthetic in these cases because it does not appear in otherwise identical phonological contexts when the verb stem does not contain a yer, as in $(18 b)$.

(18) Polish prefixed verbs

\begin{tabular}{|c|c|c|c|c|}
\hline \multicolumn{3}{|c|}{ a. Verb stems with yers ${ }^{12}$} & \multirow{2}{*}{\multicolumn{2}{|c|}{ b. Verb stems without yers }} \\
\hline Imperfective & Perfective & & & \\
\hline $\mathrm{z}+\widehat{\mathrm{d} z} \underline{\varepsilon} \mathrm{r}-\mathrm{at} \bar{c}$ & $\mathrm{z} \underline{\varepsilon}+\mathrm{dz}-\varepsilon \widehat{\mathrm{t} t} \underline{\epsilon}$ & 'to tear off' & $\mathrm{z}+\mathrm{dz \ell} \varepsilon \mathrm{mn} \widetilde{\mathrm{t}} \widehat{\epsilon}$ & 'to take a nap' \\
\hline $\mathrm{f}+\widehat{\mathrm{t} 6} \underline{\varepsilon} \mathrm{r}-\mathrm{atc}$ & $\mathrm{v} \underline{\varepsilon}+\mathrm{ts}-\varepsilon \widehat{\varepsilon t \underline{6}}$ & 'to rub in' & $\mathrm{f}+\mathrm{tssepat \epsilon}$ & 'to beat' \\
\hline
\end{tabular}

While we agree that yers play an important role in Polish in general, we are not convinced that proclitics in fact end in underlying yers. This is based on the observation that 'yers' show very limited activity in proclitics. For prefixes, they seem to be restricted to a certain class of verbs only, and for prepositions, they appear to be

\footnotetext{
${ }^{12}$ Note that $[\mathrm{r}]$ and $[\mathrm{z}] /[\mathrm{s}]$ alternate in these verbal forms; recall footnote 2.
} 
(variably) vocalized only in some lexical items (see Szpyra 1992). Thus, we maintain that proclitics do not end in an underlying yer; the relatively few cases in which 'yer vowels' seem to surface in proclitics can instead be treated as fixed expressions with underlying full vowels. If this is correct, proclitics would never be involved in the yer $\sim$ zero alternation.

However, positing underlying yers in proclitics does not cause any difficulty for the present analysis. In OT, yers can be analyzed as moraless vowels that are vocalized by the insertion of a mora, which violates the constraint $\operatorname{DEP}(\mu)$ (Rubach and Booij 2001). Unvocalized yers are not well-formed vowels and are thus deleted context-freely. ${ }^{13}$ We analyzed the phonologically-conditioned epenthesis in the clitics /v/ and /z/ as insertion of a full vowel, which implies violation of the constraint $\operatorname{DEP}(\mathrm{V})$ in addition to $\operatorname{DEP}(\mu)$ (although the discussion was simplified by only making reference to $\operatorname{DEP}(\mathrm{V}))$. If the proclitics are assumed to end in an underlying yer, the output forms with phonologically-conditioned epenthesis could simply be said to surface via mora insertion and therefore to only violate the constraint $\operatorname{DEP}(\mu)$ instead of both $\operatorname{DEP}(\mathrm{V})$ and $\operatorname{DEP}(\mu)$. The only difference between the two approaches is that the analysis which assumes the existence of yers would require two separate avenues of yer vocalization in proclitics: (i) a constraint that enforces yer vocalization whenever an unvocalized underlying yer is present in the following syllable, and (ii) AGREE[voi]+NoGEM/NVA, accounting for the phonologically-conditioned pattern.

\section{Coronal place assimilation}

In this section we provide a detailed description of a process we call coronal place assimilation (henceforth CPA), in particular as it applies to the Polish monoconsonantal proclitic /z/. In Sect. 3.1 we show the contexts in which CPA applies, and in Sect. 3.2 we discuss the optionality of its application. In Sect. 3.3 we focus on CPA as it applies to the proclitic /z/, and in Sect. 3.4 we briefly outline the essential parts of an analysis of optional CPA in OT. (A more complete account is postponed until Sect. 4, where the crucial interaction between CPA and epenthesis is discussed and analyzed.)

\subsection{Defining CPA}

There is abundant literature on Polish 'palatalization' processes that affect labials, coronals and velars in different contexts (see, for example, Rubach 1984; Czaykowska-Higgins 1988; Rowicka 1994; Rochoń 2000; and Ćavar 2004 for detailed reviews). In this literature, the term 'palatalization' appears to encompass many distinct processes, which include different types of consonant palatalizations before vowels as well as place and/or manner assimilation processes in consonant clusters. A subset of the latter processes has also been referred to in much of the previous

\footnotetext{
${ }^{13}$ As Rubach and Booij (2001: 35, fn. 12) put it, "[o]ne way of looking at yer deletion is to assume that the deletion comes for free, because all unsyllabifiable material is automatically stray-erased".
} 
literature as 'palatal assimilation'. This term is somewhat misleading since it describes the assimilatory alternations among dentals, alveolars, alveolo-palatals, and postalveolars, not (true) palatals. ${ }^{14}$ Furthermore, there seems to be no consensus as to which alternations are actually covered by the term 'palatal assimilation' (e.g. Rowicka 1994 includes assimilations of dentals, while Czaykowska-Higgins 1988 does not). Finally, other terms have also been used to refer to the same assimilation processes, but only as they affect certain specific segments (e.g. 'strident assimilation' is meant to apply to dental and alveolar obstruents in certain clusters; Rubach 1994). In this paper we are only concerned with the assimilation process that affects coronal clusters. In order to avoid any potential confusion, we use the term "coronal place assimilation' (CPA), which seems to describe the process in question more accurately.

In general terms, CPA is a process of regressive assimilation requiring that adjacent coronal consonants agree in subcoronal place of articulation (Sawicka 1995; Czaykowska-Higgins 1988; Rowicka 1994). CPA is often claimed to be obligatory within words and optional across clitic and word boundaries (e.g. Rowicka 1994), but see Sect. 3.2 for further discussion. Not all coronals participate in CPA equally; it appears that this process primarily involves the coronal stridents, shaded in the inventory of Polish coronals provided in (19). Since coronal stridents are the main focus of this paper, the subsequent discussion of CPA is limited to these segments only.

(19) The inventory of Polish coronals ${ }^{15}$ (Rubach 1984: 26)

\begin{tabular}{|c|c|c|c|c|c|}
\hline & DENTAL & ALVEOLAR & ALVEOLO-PALATAL & $\begin{array}{c}\text { POSTALVEOLAR/ } \\
\text { RETROFLEX }\end{array}$ & PALATAL \\
\hline STOP & $\mathrm{t} \quad \mathrm{d}$ & & & & \\
\hline NASAL & $\mathrm{n}$ & & $\mathrm{n}$ & & \\
\hline FRICATIVE & & $\mathrm{s} \quad \mathrm{z}$ & 6 & $s \quad z$ & \\
\hline AFFRICATE & & $\stackrel{\mathrm{ts}}{\mathrm{dz}}$ & $\widehat{t 6} \quad \widehat{d z}$ & $\widehat{t s s} \widehat{\mathrm{dz}}$ & \\
\hline LATERAL APPR. & & 1 & & & \\
\hline TRILL & & $\mathrm{r}$ & & & \\
\hline GLIDE & & & & & $\mathrm{j}$ \\
\hline
\end{tabular}

CPA most commonly targets alveolar stridents and assimilates them either to following alveolo-palatals (20a) or to following postalveolars (20b). Other logically pos-

\footnotetext{
${ }^{14}$ This misnomer is due to traditional descriptions of Polish that distinguish 'phonetic' and 'functional' palatals. The latter include postalveolars that "are palatals only in the sense that they can alternate with plain consonants ... and used to be phonetically 'soft' until the 15/16 ${ }^{\text {th }}$ c." (Rubach 1984: 23).

${ }^{15}$ See Keating (1991), Ladefoged and Maddieson (1996), and Hamann (2004) for arguments regarding the analysis of Polish postalveolars as slightly retroflex (or retracted), hence our choice of transcription of these phonemes as $/ \mathrm{s}, \mathrm{z}, \widehat{\mathrm{ts}}, \widehat{\mathrm{dz}} /$. Alternative transcriptions of these phonemes often found in the literature are $/ \int, 3, \widehat{t} \int, \widehat{d} 3 /$. The choice between these analyses is irrelevant to the primary topic of this paper.
} 
sible underlying sequences of stridents also occur (20c-f), but in these cases CPA does not apply as often as to the sequences shown in (20a-b) (Sawicka 1995). ${ }^{16}$

(20) CPA: coronal stridents

a. Alveolar $\rightarrow$ alveolo-palatal

$\mathrm{m}^{\mathrm{j}}$ asto but $\mathrm{m}^{\mathrm{j}} \mathrm{\varepsilon ct} \widehat{\mathrm{t}} \mathrm{c}$ 'city' (Nom./Loc.)

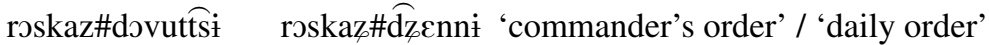

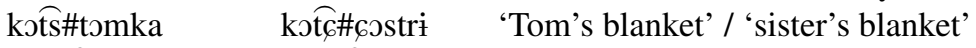

vwađৈ\#bocni vwađৈ\#zemi 'Bosnia's authorities' (Gen.) / 'land's authorities' (Gen.)

b. Alveolar $\rightarrow$ postalveolar

bes+fstidni but beș+țselni 'shameless' / 'insolent'

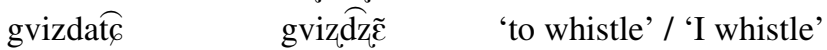

nots\#mija nots\#\#tscka 'the night passes' / 'the night waits'

vudz\#goli vudz\#z\&va 'the chief shaves' / 'the chief yawns'

c. Alveolo-palatal $\rightarrow$ postalveolar

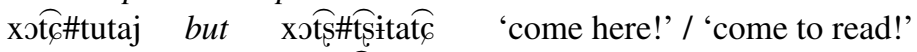

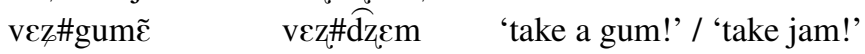

d. Postalveolar $\rightarrow$ alveolo-palatal

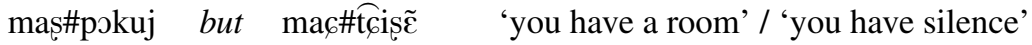

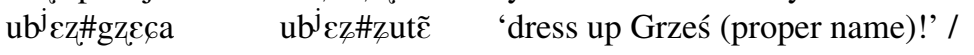

'dress up Ziuta (proper name)!'

e. Alveolo-palatal $\rightarrow$ alveolar

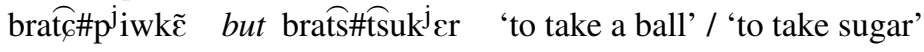

f. Postalveolar $\rightarrow$ alveolar

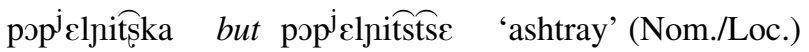

\subsection{CPA optionality}

CPA is generally claimed to be obligatory within words but optional across word or clitic boundaries (e.g. Rowicka 1994). Empirical studies suggest that there is no such categorical division, however (Dunaj 1985; Osowicka-Kondratowicz 2004, 2005; see also Sawicka 1995). Rather, the probability that CPA will apply seems to be a continuous function of the strength of the morphological boundary that separates the stridents: the weaker the boundary, the higher the probability of CPA, where boundaries from weakest to strongest are none, morpheme (-), clitic (+), and word (\#). ${ }^{17}$

\footnotetext{
${ }^{16}$ Sawicka (1995) notes that assimilation of an alveolo-palatal or a postalveolar to an alveolar, as in (20e-f), only occurs when both target and trigger are affricates and not when either segment is a fricative.

${ }^{17} \mathrm{CPA}$ at the clitic and word boundaries is also more restricted in that the consonant triggering assimilation cannot be a sonorant (Rowicka 1994).
} 
Examples of words with stridents separated by different boundaries, together with their variant forms, are shown in (21).

\section{(21) Optionality of CPA}

\section{CPA rate boundary}

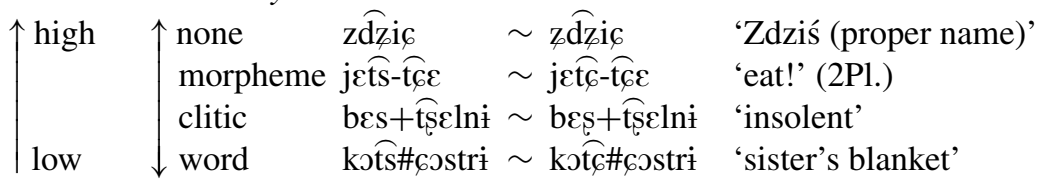

The above generalization should only be treated as a rough approximation, however. As Osowicka-Kondratowicz (2004, 2005) and Sawicka (1995) point out, the application of CPA depends on a multitude of factors such as speech rate, register, context, speaker age and individual habits, etc. Furthermore, as discussed below, there are many idiosyncrasies associated with particular words or segments.

The most comprehensive quantitative data on the application of CPA come from a production study performed by Osowicka-Kondratowicz (2004, 2005) with 90 native speakers of Polish. The study investigates the frequencies with which the coronal obstruents /t, d, s, z, ts, s, ts / assimilate to following alveolo-palatal stridents /6, $\mathrm{z}$, $\widehat{t_{6}}, \widehat{d} / \mathrm{f} / \mathrm{across}$ different boundaries (none, morpheme/suffix, pro-/enclitic) in semispontaneous speech (participants were asked questions that elicited responses containing sequences of stridents). Assimilation was determined by both auditory evaluation and acoustic analysis.

Since previous studies have shown that assimilatory processes triggered by alveolo-palatals and postalveolars pattern together (Zajda 1977; Dunaj 1985), we assume that similar results would be obtained regarding assimilation to postalveolars. This assumption is confirmed by our own study, discussed in Sect. 3.3, on the assimilation of the clitic /z/ to both alveolo-palatals and postalveolars.

The results of Osowicka-Kondratowicz's study indicate that the application of CPA is gradient: CPA ranges from slight to full assimilation. The overall results relevant for this paper are shown in (22), where the CPA column includes both full and partial assimilation. Overall, non-application of CPA was more common (69\%) than its application (31\%). Interestingly, the older group of participants (average age: 54) consistently applied assimilation more frequently than the younger group (average age: 25). This finding is compatible with the results of an older study (Zajda 1977), where application of CPA was found to be more frequent than non-application. Furthermore, the two age groups also differed in the degree of assimilation: older speakers tended to assimilate fully, while younger speakers produced partial assimilation more often than full assimilation (Osowicka-Kondratowicz 2005). This suggests a current change-in-progress towards non-application of CPA, as pointed out by Osowicka-Kondratowicz. 
(22) Mean rate of CPA (including dentals) (after Osowicka-Kondratowicz 2004)

\begin{tabular}{|c|c|c|}
\hline \multirow[t]{2}{*}{ INPUT } & \multicolumn{2}{|c|}{ OUTPUT } \\
\hline & CPA & NO CPA \\
\hline $\begin{array}{c}\text { dental obstruent }+ \text { alveolo-palatal strident } \\
/ \mathrm{t}, \mathrm{d} / \quad / 6, \mathrm{z}, \widehat{\mathrm{t} 6}, \widehat{\mathrm{d} z} /\end{array}$ & & \\
\hline $\begin{array}{c}\text { alveolar strident }+ \text { alveolo-palatal strident } \\
\qquad / \mathrm{s}, \mathrm{z}, \widehat{\mathrm{ts}} / \quad / 6, \mathrm{z}, \widehat{\mathrm{t} \epsilon}, \widehat{\mathrm{d}} \mathrm{c} /\end{array}$ & $\begin{array}{c}31 \% \\
0-37 \% \text { Y-25\%* }\end{array}$ & $\begin{array}{c}69 \% \\
0-63 \% \quad Y-75 \%\end{array}$ \\
\hline $\begin{array}{c}\text { postalveolar strident }+ \text { alveolo-palatal strident } \\
/ \mathrm{s}, \mathrm{t}_{\mathrm{s}} / \quad / 6, \mathrm{t}_{6} /\end{array}$ & & \\
\hline
\end{tabular}

${ }^{*} \mathrm{O}$ - older group of subjects (average age: 54 )

Y-younger group of subjects (average age: 25 )

Additional observations can also be made regarding the application of CPA to certain segments. Specifically, voiceless stridents undergo CPA more often than voiced ones (Sawicka 1995; Osowicka-Kondratowicz 2004, 2005), and assimilation occurs more frequently between a fricative and an affricate (in either order) as opposed to between two fricatives or two affricates (Osowicka-Kondratowicz 2004, 2005; Dunaj

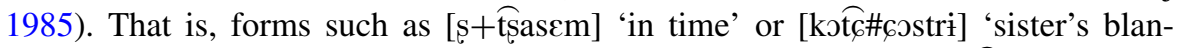
ket' have a higher probability of surfacing than forms such as [ș+sazet6] 'to become

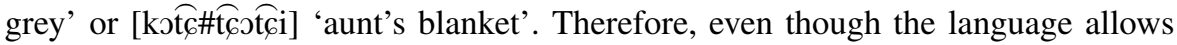
geminates in vowel-adjacent contexts such as these, the data suggest that creating a geminate is probabilistically disfavored in cases of variation (i.e. when there is a choice between a form with or without a geminate).

\subsection{CPA in the proclitic /z/}

The data of most relevance to the primary topic of this paper concern the application of CPA across a proclitic boundary, and more specifically its application to the monoconsonantal coronal clitic /z/, as shown in (23).

(23) Optional CPA in the proclitic /z/

a. Optional assimilation to alveolo-palatals

\begin{tabular}{|c|c|c|c|}
\hline $\mathrm{z}+\widehat{\mathrm{d} z} \mathrm{v}^{\mathrm{j}} \mathrm{ig}^{\mathrm{j}} \varepsilon \mathrm{m}$ & $\sim$ & $\mathrm{z}+\widehat{\mathrm{d} z} \mathrm{v}^{\mathrm{j}} \mathrm{ig}^{\mathrm{j}} \mathrm{cm}$ & 'with a crane' \\
\hline $\mathrm{z}+\mathrm{z} \hat{\mathrm{\varepsilon}}$ & $\sim$ & $z+z \tilde{\varepsilon} b n \widetilde{2} \widetilde{t} \epsilon$ & 'to become cold' \\
\hline & $\sim$ & $6+\overparen{\text { tcisisite }}$ & 'to soften (the volum \\
\hline & $\sim$ & $6+6$ ancm & 'with hay' \\
\hline
\end{tabular}

b. Optional assimilation to postalveolars
$\mathrm{z}+$ dzungli
$\sim \mathrm{z}+$ dqungli
'from a jungle'
$\mathrm{z}+\mathrm{z} a \mathrm{ab} \tilde{\mathrm{s}}$
$\sim$ z+ząabõ
$\mathrm{s}+\widehat{\mathrm{t} s} \mathrm{kafk} \tilde{\mathrm{o}}$

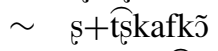
'with a frog'
$\mathrm{s}+$ sazetc
$\sim$ S+sazet $\widehat{C}$
'with hiccups'
'to become gray'

The results of the experiment by Osowicka-Kondratowicz $(2004,2005)$ described in Sect. 3.2 indicate that the clitic/z/ undergoes CPA slightly more frequently 
than final stridents of other proclitics. This is plausibly due to the fact that $/ z /$ is not syllabified separately from its host (Rubach and Booij 1990; Sawicka 1995; Rochon 2000). This is in contrast to longer proclitics in which the final consonant is never resyllabified to form part of an onset but always remains in coda position.

The table in (24) shows the frequencies with which CPA applied to the clitic /z/ in Osowicka-Kondratowicz's study. On average, /z/ underwent CPA in 27 percent of utterances. ${ }^{18}$ Again, older participants applied assimilation more often than younger participants.

(24) Mean rate of CPA: the clitic /z/ (after Osowicka-Kondratowicz 2004)

\begin{tabular}{|c|c|c|c|c|}
\hline \multirow[t]{2}{*}{ INPUT } & \multicolumn{4}{|c|}{ OUTPUT } \\
\hline & \multicolumn{2}{|c|}{ CPA } & \multicolumn{2}{|c|}{ NO CPA } \\
\hline \multirow{2}{*}{$\begin{array}{c}|\mathrm{z}|+\text { alveolo-palatal strident } \\
{[\mathrm{z}, 6, \widehat{\mathrm{dz}}, \widehat{\mathrm{t} 6}]}\end{array}$} & \multicolumn{2}{|c|}{$27 \%$} & \multicolumn{2}{|c|}{$73 \%$} \\
\hline & O-35\% & Y-19\% & $0-65 \%$ & Y-81\% \\
\hline
\end{tabular}

We have collected additional data relevant to the current discussion. Twentyone native speakers of Polish were recruited for our experiment in August 2008 in Kraków, Poland. They listened to a fictitious story over headphones and responded to questions about the story content. The questions elicited responses that included sequences of the clitic /z/ with stems beginning with alveolo-palatal and postalveolar stridents. The participants' speech was recorded and stored for acoustical analysis. See the Appendix for a more detailed description of the study.

The presence or absence of CPA was determined by comparing the spectral properties of the clitic to the properties of the following consonant, separately for each token. This was done by calculating the center of gravity $(\mathrm{CoG})$ for each target consonant (see the Appendix for the exact procedure). A difference in $\mathrm{CoG}$ between /z/ and the following consonant was calculated for each test token. A low difference in $\mathrm{CoG}$ was assumed to indicate a high degree of assimilation, and conversely, a high difference in CoG was assumed to indicate a low degree of assimilation. The measurements were log-transformed for the purposes of statistical analysis.

The results were averaged by item and analyzed by means of a repeated measures ANOVA on the within-item variable age group (young, old), and the betweenitem variables that describe the first consonant of the stem: place of articulation (alveolo-palatal, postalveolar), manner of articulation (fricative, affricate), and voicing (voiced, voiceless).

The results confirmed that CPA applies equally in contexts where /z/ assimilates to alveolo-palatals and to postalveolars, since no difference between the two contexts

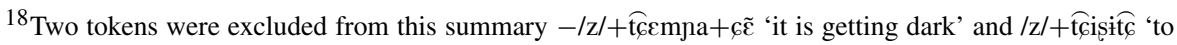
soften (the volume)'. These tokens are different from all other examples in that they are represented in the Polish writing system in a way that shows the application of CPA. That is, the clitic /z/ in both of the cited examples is always written as ' $\hat{s}$ ' [c], while in all other cases it is written as either ' $\mathrm{z}$ ' or-for devoiced prefixes-as 's', regardless of whether it undergoes CPA or not. This fact very likely skewed the results by inducing a much higher rate of CPA $(69 \%)$.
} 
was found $[F=1.08]$. Furthermore, no statistically significant difference was found between fricatives and affricates $[F<1]$, nor between voiced and voiceless segments $[F<1]$. There was, however, a significant effect of age group $[F(1,8)=9.5$; $p<.05]$. The results provided further support for Osowicka-Kondratowicz's (2005) claim that Polish is currently undergoing a gradual change in the direction of loss of CPA: the older group of participants ( $n=6$; average age: 54 , ranging from 43 to 61 ) applied assimilation more often than the younger group of participants $(n=15$; average age 27, ranging from 24 to 31). Finally, and as in Osowicka-Kondratowicz's (2004, 2005) study, CPA was found to be gradient and varied from slight to full assimilation.

For the purposes of illustrating the approximate rates of CPA, the data were divided by assuming that assimilation had applied when the difference in CoG between the clitic /z/ and the following consonant was below $1,000 \mathrm{~Hz}$, and that assimilation had not applied when the difference in $\mathrm{CoG}$ was at least $1,000 \mathrm{~Hz}$. This is shown in (25), separately for fricative- and affricate-initial stems. ${ }^{19}$ Furthermore, in order to provide a clearer picture of the degree of assimilation, both tables include percentages of what we assume to be full assimilation (f), with a difference in CoG below $500 \mathrm{~Hz}$, and of what we assume to be complete lack of assimilation (1), with a difference in $\mathrm{CoG}$ of at least $1,500 \mathrm{~Hz}$.

The results show that the overall rate of CPA in the clitic/z/ was 50 percent, slightly higher in tokens with affricate-initial stems than in tokens with fricativeinitial stems. Full assimilation occurred fairly rarely (26\%), and was slightly more common in tokens with affricate-initial stems than in tokens with fricative-initial stems (28\% vs. 24\%). Conversely, complete lack of assimilation was overall somewhat more common $(30 \%)$, and occurred more frequently in tokens with fricativeinitial stems than in tokens with affricate-initial stems (33\% vs. 27\%).

Mean rate of $C P A$

\begin{tabular}{|c|c|c|}
\hline \multirow{2}{*}{ INPUT $(N=672)$} & \multicolumn{2}{|c|}{ OUTPUT } \\
\hline & CPA & NO CPA \\
\hline \multirow[t]{2}{*}{$\begin{array}{l}|\mathrm{z}|+\text { alveolo-palatal or postalveolar } \\
\text { fricative }[\mathrm{z}, \mathrm{z}, \mathrm{s}, \mathrm{s}]+\mathrm{V}\end{array}$} & $\begin{array}{c}47 \% \\
(f-24 \%)\end{array}$ & $\begin{array}{c}53 \% \\
(1-33 \%)\end{array}$ \\
\hline & O-51\% Y-45\% & $0-49 \% \quad Y-55 \%$ \\
\hline \multirow[t]{2}{*}{$\begin{array}{l}\mid \mathrm{z} /+ \text { alveolo-palatal or postalveolar } \\
\text { affricate }[\widehat{\mathrm{d} z}, \widehat{\mathrm{dz}}, \widehat{\mathrm{t} c}, \widehat{\mathrm{t}} \mathrm{s}]\end{array}$} & \multirow{2}{*}{$\begin{array}{c}52 \% \\
(\mathrm{f}-28 \%)\end{array}$} & $\begin{array}{c}48 \% \\
(1-27 \%)\end{array}$ \\
\hline & & $0-47 \% \quad Y-48 \%$ \\
\hline
\end{tabular}

$* \mathrm{O}(n=6)$-older group of subjects (average age: 54, ranging from 43 to 61 )

$\mathrm{Y}(n=15)$-younger group of subjects (average age 27, ranging from 24 to 31 )

$\mathrm{f}$ - full assimilation (difference in CoG: below $500 \mathrm{~Hz}$ )

l—complete lack of assimilation (difference in CoG: at least 1,500 Hz)

Before we proceed with the analysis, we would like to emphasize that while the reported percentages are useful for illustration, they should be treated with caution due

\footnotetext{
${ }^{19}$ All fricative-initial stems were singleton-onset fricatives followed by a vowel. The stems with fricatives beginning a complex onset, which trigger optional epenthesis, are discussed in Sect. 4.3.
} 
to the somewhat arbitrary division between application and non-application of assimilation. The reader should keep in mind that the statistical analysis was performed on continuous data, and that these data - not the percentages provided in (25) - are the basis for the claims of change in progress.

\subsection{Analysis}

Since we are primarily concerned here with assimilation processes that apply to coronal stridents, for the purposes of our analysis we follow Czaykowska-Higgins (1988) in adopting a definition of CPA restricted to these segments. Accordingly, we assume that CPA is triggered by the markedness constraint AGREE[cor], which penalizes sequences of coronal stridents that do not agree in subcoronal place of articulation. Underlying coronal segments that surface with a different place of articulation violate the faithfulness constraint IDENT[cor]. This constraint is assumed to be violated when a coronal segment changes its place either to another coronal place (e.g. alveolar to alveolo-palatal) or to a non-coronal place (e.g. alveolar to dorsal); that is, IDENT[cor] requires that a coronal in the input remain the same type of coronal in the output. Informal definitions of these two constraints are provided in (26).

\section{Informal definitions of constraints responsible for CPA}

AGREE[cor] Adjacent coronal stridents must have the same value for subcoronal place of articulation (alveolar, alveolo-palatal, postalveolar).

IDENT[cor] Input and output correspondents must have the same value for subcoronal place of articulation (alveolar, alveolo-palatal, postalveolar).

One straightforward-seeming way to account for the optionality of CPA in OT is to assume that the constraints AGREE[cor] and IDENT[cor] are 'tied' (i.e. crucially unranked with respect to each other). ${ }^{20}$ Under this assumption, two candidates can surface as optimal, as shown in (27). ${ }^{21}$

(27) Optionality of CPA

\begin{tabular}{|c|c|c|}
\hline$|z+d z|$ & AGREE[cor] & IDENT[cor] \\
\hline a. $\rightarrow \mathrm{z}+\mathrm{d} z$ & $*$ & 2 \\
\hline b. $\rightarrow z+d z$ & & $\sum$ \\
\hline
\end{tabular}

In Sect. 4 we show how CPA interacts with epenthesis, which requires a different and perhaps less straightforward-seeming way to account for its optionality.

\footnotetext{
${ }^{20}$ See Müller (1999) for extensive discussion of various other technical interpretations of the otherwise deceptively simple notion of a constraint tie.

${ }^{21}$ The regressive direction of CPA can be achieved with a positional variant of IDENT[cor], as already discussed for the regressive direction of voicing assimilation in Sect. 2.1, footnote 3.
} 


\section{CPA and epenthesis: contingent optionality}

In this section we discuss how the optionality of CPA described in the previous section crucially impinges on the application of epenthesis. Recall from Sect. 2 that the potential creation of a non-vowel-adjacent geminate by voicing assimilation blocks the application of assimilation and triggers the application of epenthesis instead; this same condition also blocks the application of CPA and triggers the application of epenthesis instead. But because CPA is optional, epenthesis also applies only optionally in such situations; in other words, if CPA does not apply and thereby does not create a potential non-vowel-adjacent geminate, then epenthesis need not and does not apply.

\subsection{Optional epenthesis}

As shown in (28), epenthesis applies optionally in just those cases where application of CPA (in conjunction with obligatory voicing assimilation) is otherwise expected to create a non-vowel-adjacent geminate. The grammatical forms on the left are variants in which neither CPA nor epenthesis has applied, while those on the right are variants in which epenthesis has applied; the ungrammatical forms on the far right show that application of CPA is impossible in such cases.

(28) Optional epenthesis in the proclitic /z/

a. Optional epenthesis before alveolo-palatals in initial clusters

\begin{tabular}{|c|c|c|c|c|}
\hline z+zrudwa & $\sim$ & ze + zrudwa & 'from a spring' & $*_{z}+$ zrudwa \\
\hline $\mathrm{z}+\mathrm{zrcbak}^{\mathrm{j}} \mathrm{cm}$ & $\sim$ & $\mathrm{z} \varepsilon+\mathrm{zrcbak}^{\mathrm{j}} \varepsilon \mathrm{m}$ & 'with a colt' & $*_{\mathrm{z}}+\mathrm{zrcbak}^{\mathrm{j}} \mathrm{\varepsilon m}$ \\
\hline $\mathrm{s}+6$ fitem & $\sim$ & $\mathrm{z} \varepsilon+6$ fitem & 'with dawn' & ${ }^{*} 6+6$ fitem \\
\hline$s+6 f^{j}$ ว̃tini & $\sim$ & $\mathrm{z \varepsilon}+{ }_{6} \mathrm{f}^{\mathrm{j}}$ วัtīni & 'from a temple' & ${ }^{*} 6+{ }_{6} \mathrm{f}^{\mathrm{j}}$ ว̆tini \\
\hline
\end{tabular}

b. Optional epenthesis before postalveolars in initial clusters

\begin{tabular}{|c|c|c|c|c|}
\hline z+zviru & $\sim$ & $\mathrm{z} \varepsilon+\mathrm{zv}$ viru & 'from gravel' & $*_{\mathrm{z}}+\mathrm{z}$ viru \\
\hline 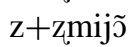 & $\sim$ & $\mathrm{z} \varepsilon+\mathrm{z} m i j \tilde{\jmath}$ & 'with a viper' & $*_{\mathrm{Z}}+\mathrm{zmij} \mathrm{m}$ \\
\hline$+s$ & $\sim$ & $\mathrm{z} \varepsilon+$ slaxt & 'with nobility' & $*_{S}+$ slaxt \\
\hline lk̃̃ & $\sim$ & $\mathrm{z} \varepsilon+$ spilkõ & 'with a pin' & lk̃̃ \\
\hline
\end{tabular}

The optional variants in (28) are precisely the expected consequences of the form of our analysis of epenthesis coupled with the fact that CPA is optional. Recall from our analysis of epenthesis in Sect. 2 that epenthesis is only truly triggered when the outcome would otherwise be a non-vowel-adjacent geminate due to the otherwise expected application of assimilation; the application of epenthesis is thus contingent on the applicability of assimilation. Epenthesis is obligatory when the consonants in question differ at most in voicing because voicing assimilation is otherwise obligatory: if epenthesis did not apply, then voicing assimilation would, creating a forbidden non-vowel-adjacent geminate. This is illustrated again in (29), repeated from $(7 b) /(17 b)$. 
(29) Obligatory vowel epenthesis, contingent on obligatory voicing assimilation

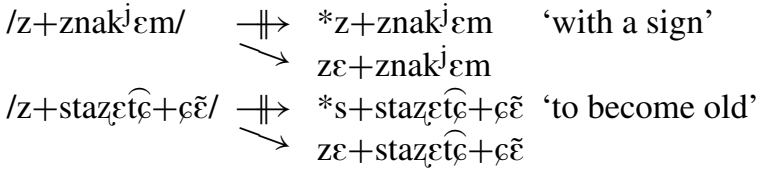

Matters are different, however, when the assimilation process in question is CPA. Because CPA is optional, it is only in danger of creating a non-vowel-adjacent geminate if it applies; if it does not apply, then the forbidden geminate is avoided without the need for epenthesis to apply. Epenthesis is thus expected to be optional in just this set of cases, as the facts bear out in (28); this contingent interaction between epenthesis and CPA is illustrated in (30).

(30) Optional vowel epenthesis, contingent on optional CPA

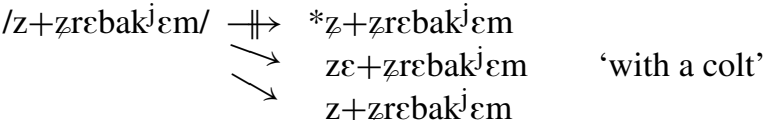

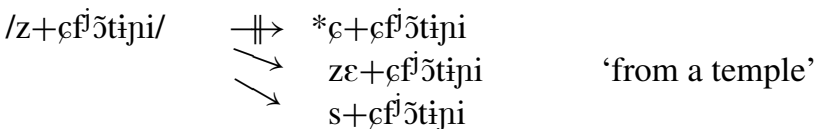

\subsection{Analysis}

Recall from the analysis in Sect. 2 that the constraint ranking required for epenthesis to be contingent on voicing assimilation is as in (31a) below.

\section{(31) Ranking for contingent interaction}

a. Between voicing assimilation and epenthesis NoGEM/NVA, AGREE[voi] $\gg \operatorname{DEP}(\mathrm{V}) \gg$ IDENT[voi]

b. Between CPA and epenthesis-unsuccessful attempts
i. NOGEM/NVA, AGREE[cor] $\gg \operatorname{DEP}(V) \gg \operatorname{IDENT}[$ cor]
ii. NoGEM/NVA $\gg$ AGREE[cor], DEP(V), IDENT[cor]

Simply replacing '[voi]' with '[cor]' in the AGREE and IDENT constraints as in (31b.i) is not sufficient to account for the contingent interaction between CPA and epenthesis, however, due to the optionality of these latter processes in the relevant sets of contexts. But taking the straightforward-seeming account of the optionality of CPA in terms of a 'tie' between AGREE[cor] and IDENT[cor] (as illustrated in (27)) and coupling it with the schema in (31b.i), as shown in (31b.ii), leads immediately to a paradox: if AGREE[cor] and IDENT[cor] are crucially unranked with respect to each other, as required by (27), then $\operatorname{DEP}(\mathrm{V})$ cannot be crucially ranked between them, as required by (31b.i). (Note that in this case it is necessary to introduce a ranking between NoGEM/NVA and the other constraints.) The paradox is illustrated in more detail in the tableaux that follow.

In the tableaux in (32) the constraints AGREE[cor] and IDENT[cor] are tied, which leads to them also being tied with the intervening constraint DEP(V). However, while 
the two possible optimal candidates are correctly predicted in the second tableau (ii), this solution leads to an incorrect result in the first tableau (i), where the candidate with epenthesis is predicted as a third possible option when in fact it should be eliminated.

(32) Tie between AGREE[cor] and IDENT[cor] leads to a tie with DEP(V)

i. $C P A \sim$ no $C P A$

\begin{tabular}{|c|c|c|c|c|}
\hline$|\mathrm{z}+\widehat{\mathrm{dz}}|$ & NoGEM/NVA & AGREE[cor] & DEP(V) & IDENT[cor] \\
\hline a. $\rightarrow \quad[z+\widehat{d z}]$ & & * & 1 & 1 \\
\hline b. $\rightarrow \quad[\mathrm{z}+\widehat{\mathrm{dz}}]$ & & & 1 & $*$ \\
\hline c..!!! $\rightarrow[\mathrm{z \varepsilon}+\mathrm{dz}]$ & & & 1 & 1 \\
\hline
\end{tabular}

ii. Epenthesis $\sim$ no $C P A$

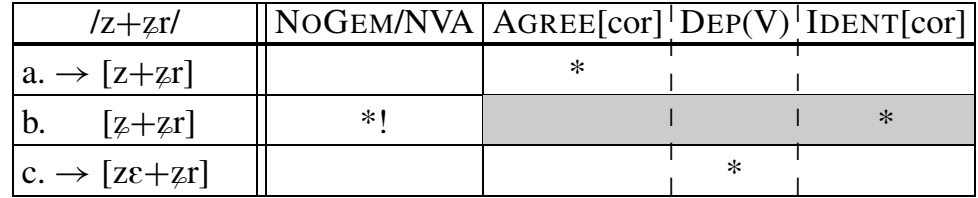

This could be fixed by establishing an immutable ranking between $\operatorname{DEP}(\mathrm{V})$ and IDENT[cor], but this would of course eliminate any optionality. Another potential solution would be to rank DEP(V) above both AGREE[cor] and IDENT[cor], as in the tableaux in (33). While this correctly eliminates the epenthetic candidate in the first tableau (i), it also incorrectly eliminates the same type of candidate in the second tableau (ii).

(33) Tie between AGREE[cor] and IDENT[cor] with higher-ranked DEP(V)

i. $C P A \sim$ no $C P A$

\begin{tabular}{|l||c|c|c|c|}
\hline \multicolumn{1}{|c|}{$/ \mathrm{z}+\widehat{\mathrm{dz}} !$} & NoGEM/NVA & DEP(V) & AGREE[cor] & IDENT[cor] \\
\hline a. $\rightarrow[\mathrm{z}+\widehat{\mathrm{dz}}]$ & & & $*$ & । \\
\hline b. $\rightarrow[\mathrm{z}+\widehat{\mathrm{dz}}]$ & & & & $*$ \\
\hline c. $\quad[\mathrm{z} \varepsilon+\widehat{\mathrm{dz}}]$ & & $* !$ & & । \\
\hline
\end{tabular}

ii. Epenthesis $\sim$ no $C P A$

\begin{tabular}{|l||c|c|c|c|}
\hline \multicolumn{1}{|c|}{$/ \mathrm{z}+\mathrm{zr} /$} & NOGEM/NVA & DEP(V) & AGREE[cor] & IDENT[cor] \\
\hline a. $\rightarrow[\mathrm{z}+\mathrm{zr}]$ & & & $*$ & \\
\hline b. $\quad[\mathrm{z}+\mathrm{zr}]$ & $* !$ & & \multicolumn{2}{|l|}{$*$} \\
\hline c. $! ! ![\mathrm{z} \varepsilon+\mathrm{zr}]$ & & $* !$ & \multicolumn{2}{|l}{} \\
\hline
\end{tabular}

The tied-constraint approach thus results in a paradox because the constraints $\operatorname{DEP}(\mathrm{V})$ and AGREE[cor] must be simultaneously ranked and crucially unranked 
with respect to each other in order to account for the two types of variation. This paradox can be avoided by adopting a different approach to the analysis of optionality. While several approaches in the literature are in principle compatible with our overall analysis, we adopt here the essence of the approach to variation proposed by Coetzee (2009a). ${ }^{22}$ Alternatives are discussed briefly at the end of this section.

Under this approach, a constraint can have two (or more) copies that occupy different positions in the constraint hierarchy; for expository purposes, we will refer to the lowest-ranked copy of a constraint as the original and any higher-ranked copy as a clone. Prince (1998: 13) notes that "a constraint cannot be meaningfully repeated in the same hierarchy [because] ...C $\gg \ldots \mathrm{C} \ldots$ is completely equivalent to ...C $\gg \ldots$.., and so the original and its clones must be distinct somehow. In Pater's work on exceptionality, clones are indexed to apply only to particular (sets of) forms: for those forms to which a clone applies, the higher rank of the clone disguises the lower rank of the original; for all other forms, the clone is inactive and the original holds sway.

We follow Coetzee (2009a) in assuming instead that clones are stochastically active: whether a clone is active in its higher position in the hierarchy is probabilistically dependent on any of the sorts of internal and external factors that play a role in linguistic variation. ${ }^{23}$ The higher the probability of the activity of a clone, the more likely the pattern predicted by the interaction of the clone with other constraints. The lower the probability of the activity of a clone, the more likely the pattern predicted by the interaction of the original with other constraints.

Returning to the analysis of the variation patterns of interest here: we propose that AGREE[cor] is the constraint that has two copies in the constraint hierarchy of Polish, as illustrated in (34) and (35). The original resides below IDENT[cor] and the clone resides above $\operatorname{DEP}(\mathrm{V})$, which is itself ranked above IDENT[cor]. When the clone is inactive, as shown in (34), then disagreement in coronal place (candidate (a)) is optimal in both cases.

(34) When the AGREE[cor] clone is inactive

i. No CPA

\begin{tabular}{|c|c|c|c|c|}
\hline$|z+\widehat{d} \bar{y}|$ & NOGEM/NVA '(AGREE[cor]) & $\operatorname{DEP}(\mathrm{V})$ & IDENT[cor] & AGREE[cor] \\
\hline a. $\rightarrow[\mathrm{z}+\widehat{\mathrm{d} z}]$ & & & & $*$ \\
\hline b. $\quad[z+\widehat{d} z]$ & I & & $* !$ & \\
\hline c. $[\mathrm{z} \varepsilon+\widehat{\mathrm{dz}}]$ & & $* !$ & & \\
\hline
\end{tabular}

\footnotetext{
${ }^{22}$ This approach has its roots in the use of lexically-indexed constraints to account for patterns of lexical exceptionality (Ito and Mester 1999; Pater 2000, 2006, 2008; Pater and Coetzee 2005; Becker 2009; Becker and Fainleib 2009; Coetzee 2009b; see also Kenstowicz 2005 for a similar approach to loanword adaptation); we adopt the useful term clone in the following discussion from Pater's and Becker's recent works.

${ }^{23}$ Coetzee's focus is on lexical frequency, but other factors are not excluded in principle.
} 


\section{ii. No epenthesis}

\begin{tabular}{|l||c|c|c|c|c|}
\hline \multicolumn{2}{|c||}{ z+zrel } & NoGEM/NVA'(AGREE[cor]) & DEP(V) & IDENT[cor] & AGREE[cor] \\
\hline a. $\rightarrow[\mathrm{z}+\mathrm{zr}]$ & & & & & $*$ \\
\hline b. $\quad[\mathrm{z}+\mathrm{zr}]$ & $* !$ & & & $*$ & \\
\hline c. $\quad[\mathrm{z} \varepsilon+\mathrm{zr}]$ & & & $* !$ & & \\
\hline
\end{tabular}

When the clone is active, on the other hand, disagreement is not tolerated; this leads to CPA in (35i), candidate (b), when the resulting geminate is followed by a vowel or (as in the tableau) in the case of an affricate-initial stem where no geminate is in danger of being created. When the potential geminate is followed by a consonant as in (35ii), however, then NoGEM/NVA rules out CPA and candidate (c), with epenthesis, is selected instead.

(35) When the AGREE[cor] clone is active

i. $C P A$

\begin{tabular}{|c|c|c|c|c|c|}
\hline $\mid \mathrm{z}+\mathrm{d} \mathrm{z} /$ & NOGEM/NVA & 'AGREE[cor] & $\operatorname{DEP}(\mathrm{V})$ & IDENT[cor] & AGREE[cor] \\
\hline a. $\quad[\mathrm{z}+\widehat{\mathrm{d} z}]$ & & $* !$ & & & $*$ \\
\hline b. $\rightarrow[\mathrm{z}+\widehat{\mathrm{dz}}]$ & & I & & $*$ & \\
\hline c. $[\mathrm{z} \varepsilon+\widehat{\mathrm{dz}}]$ & & । & $* !$ & & \\
\hline
\end{tabular}

\section{ii. Epenthesis}

\begin{tabular}{|c|c|c|c|c|c|}
\hline $\mid z+z \mathrm{re} /$ & NOGEM/NVA & AGREE[cor] & $\operatorname{DEP}(\mathrm{V})$ & IDENT[cor] & AGREE[cor] \\
\hline$[\mathrm{z}+\mathrm{zr}]$ & 1 & $* !$ & & & $*$ \\
\hline b. $\quad[\mathrm{z}+\mathrm{zr}]$ & $* !$ & I & & $*$ & \\
\hline c. $\rightarrow[\mathrm{z} \varepsilon+\mathrm{zr}]$ & 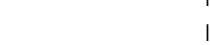 & 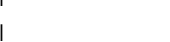 & $*$ & & \\
\hline
\end{tabular}

This approach avoids the paradox of 'tied' constraints essentially by defining a constraint tie more broadly: AGREE[cor] is tied with respect to both IDENT[cor] and $\operatorname{DEP}(\mathrm{V})$, not just the former, but $\operatorname{DEP}(\mathrm{V})$ and IDENT[cor] are still crucially ranked with respect to each other. Other approaches to variation in OT that can replicate this broader definition of a tie in some way should thus be equally successful in accounting for the pattern. In Stochastic OT (Boersma 1998; Boersma and Hayes 2001), for example, constraints are associated with functions that probabilistically determine each constraint's precise position within a defined slice of a continuous scale. Crucially, these constraint slices can overlap such that the precise position of two constraints $\mathrm{A}$ and $\mathrm{B}$ along the scale can sometimes result in the ranking $\mathrm{A} \gg \mathrm{B}$ and other times in the ranking $\mathrm{B} \gg \mathrm{A}$. The contingent optionality pattern can thus be accounted for if the AGREE[cor] slice overlaps with both the DEP(V) and IDENT[cor] slices, which do not overlap with each other.

To repeat the main point here: the pattern of optionality that we find in Polish, with the optionality of epenthesis being contingent on the optionality of CPA, is precisely what one expects from the approach that we have adopted throughout this paper of accounting for 'sufficiently similar' adjacent consonant avoidance in terms of the interaction of 
antigemination and assimilation. Indeed, it is hard to imagine how the facts could be otherwise described except by pure stipulation. Epenthesis between consonants differing at most in voicing is obligatory, and voicing assimilation also happens to be obligatory; epenthesis between consonants differing at most in (voicing and) subcoronal place is optional, and CPA also happens to be optional. These apparent coincidences are expected and explained under the current proposal.

\subsection{Parallelism of changes in progress}

A further notable finding in our experimental results, confirming the results of Osowicka-Kondratowicz $(2004,2005)$, is the parallelism of two evident changes in progress: older speakers have higher rates of epenthesis and of CPA than do younger speakers, indicating a diachronic decline in the application of both processes. The table in (36) below summarizes the rates of epenthesis that we found in our data (see the experimental procedures described in Sect. 3.3 and the Appendix). Overall, the older group of speakers exhibited a much higher rate of epenthesis than did younger speakers $\left[\chi^{2}(1)=7.04, p<.01\right]$; recall from the results reported in Sect. 3.3 (both ours and those of Osowicka-Kondratowicz) that a similar overall difference between older and younger speakers is evident in the application of CPA. ${ }^{24}$

(36) Mean rate of epenthesis

\begin{tabular}{|c|c|c|c|c|}
\hline \multirow[t]{2}{*}{ INPUT $(N=336)$} & \multicolumn{4}{|c|}{ OUTPUT } \\
\hline & EPEI & ESIS & NOE & HESIS \\
\hline \multirow{2}{*}{$\begin{array}{c}\mid \mathrm{z} /+ \text { alveolo-palatal or postalveolar } \\
\text { fricative }[\mathrm{z}, \mathrm{z}, 6, \mathrm{~s}]+\mathrm{C}\end{array}$} & \multicolumn{2}{|c|}{$82 \%$} & \multicolumn{2}{|c|}{$18 \%$} \\
\hline & $0-92 \%$ & Y-79\% & 0-8\% & Y-21\% \\
\hline
\end{tabular}

${ }^{*} \mathrm{O}(n=6)$-older group of subjects (average age: 54 , ranging from 43 to 61 )

$\mathrm{Y}(n=15)$ - younger group of subjects (average age 27, ranging from 24 to 31 )

That these two changes should be occurring together is again completely expected under our analysis, and can be understood in the following way: the grammar of older speakers is more sensitive than the grammar of younger speakers to factors that promote the general activity of the AGREE[cor] clone. The more active the clone, the higher the rates of both CPA and epenthesis (as evidenced by the data from older speakers). The less active the clone, the lower the rates of both processes (as evidence by the data from younger speakers).

A reviewer points out that two co-occurring optional processes do not have to be linked together. We fully agree with this statement. However, the pattern under discussion is not simply about two optional processes that happen to co-occur in the language. CPA is an optional process across the board, but epenthesis is prevailingly an obligatory process, for both clitics /v/ and /z/, as discussed in Sect. 2. Epenthesis is only optional in very specific cases, with the clitic/z/ and only when the stem begins with an alveolopalatal or a postalveolar fricative that begins a complex cluster-the precise conditions in which CPA is expected to be applicable but blocked. These very specific facts are

\footnotetext{
${ }^{24}$ In a much earlier study, Zajda (1977) reports very high rates of CPA. The general lack of independent sources documenting the optionality of epenthesis in these contexts suggests that its rates were so high as to be (perceived as) categorical - at least until relatively recently, as rates of CPA have declined.
} 
explained by linking the relevant processes in the way we have proposed, and would otherwise be left as a remarkable set of coincidences.

\subsection{Factors affecting stochastic activity}

If the factors playing into the activity of the AGREE[cor] clone were exactly the same across the board, then we would expect the following pattern: roughly the same rates of CPA and epenthesis when the clone is active, and roughly the same rates of no CPA and no epenthesis when the clone is inactive. This is not the case, however, indicating that there are at least some significantly different factors playing into the activity of the clone in each type of example. This is not much of a surprise, given that the phonological contexts of the examples crucially differ from each other: a (potential) single-voweladjacent geminate or a fricative+affricate sequence in the case of optional CPA and a (potential) non-vowel-adjacent geminate in the case of optional epenthesis.

Comparing again the rates of epenthesis in (37) with the rates of CPA tabulated in (25), we see that epenthesis applies far more frequently than not whereas there is a more or less equal distribution of CPA and no CPA. This is not expected if the stochastic activity of the AGREE[cor] clone is not sensitive to the phonological difference between these sets of forms, and so we assume that it must be sensitive to this difference: the non-vowel-adjacent context promotes activity of the clone more than the single-voweladjacent context.

There are also other possible reasons why the rates of CPA and epenthesis do not match. First of all, the change is currently in progress, and therefore the rates are simply not stable. Furthermore, if we assume such an intricate pattern of contingency between CPA and epenthesis, it is not surprising that some time is needed for the grammar to adjust. Importantly, the change progresses the way our analysis would predict: the rates of CPA begin declining first, which in turn causes the decline of epenthesis rates (in the relevant contexts). A factor that possibly slows down the optional epenthesis decline is the influence from general properties of the process itself. As already pointed out, epenthesis is predominantly obligatory in the language. The contexts in which it is optional are very specific and in fact not very common. Therefore, speakers might tend to overgeneralize its application simply due to this influence.

A reviewer also notes that CPA applies more often in fast, casual speech, while epenthesis is more common in careful speech. This is not a surprise given the substance of these two types of registers: fast, casual speech commonly blurs the boundaries between segments, morphemes, words, and so on; careful speech, on the other hand, commonly results in more easily recoverable boundaries between these elements. In other words, we expect more overlap in articulations (co-articulation and assimilation) in casual speech and maximization of the separation between articulations in careful speech-precisely what we find in this case.

The same reviewer goes on to suggest that the discrepancies in the rates of CPA and epenthesis in casual speech and careful speech constitute an argument against linking the two processes in the way we have proposed here. We believe that this conclusion is due to a subscription to the intuitively appealing assumption that a particular register (or even a particular utterance) is associated with a particular grammar, a widespread assumption that has nevertheless, so far as we know, not been firmly established as necessary in the literature. We assume instead that 'register' is simply one of the many factors that may influence the stochastic activity of a clone, and furthermore that the nature of the locus of potential application of a process is also a factor. 
Thus, even in the simple case where there is just one variable process that applies more often in some register, we assume that a clone is more or less likely to be active in the evaluation of each potential locus of application of the process within that register. Whether or not a clone is active is determined at the level of the individual locus of application of a process involving that clone, with the nature of the locus and the register being factors affecting the clone's activity-among many other factors, as outlined further above.

Returning to the situation in Polish, 'casual speech' is characterized by higher rates of CPA and lower rates of epenthesis, and 'careful speech' is characterized by lower rates of CPA and higher rates of epenthesis. What we interpret this to mean is the following. In the individual evaluation of potential loci of CPA application, casual speech results in higher likelihood of activation of the AGREE[cor] clone and careful speech results in lower likelihood of this activation. In the individual evaluation of potential loci of epenthesis application, on the other hand, the reverse must be the case: careful speech results in higher likelihood of activation of the AGREE[cor] clone and casual speech results in lower likelihood of this activation.

\section{Concluding remarks}

In sum, the phonology of monoconsonantal proclitics in Polish provides significant evidence for the analysis of 'sufficiently similar' adjacent consonant avoidance of Baković (2005). The key to Baković's analysis is that 'sufficient similarity' between adjacent consonants is a derivative property, emerging from the interaction of strict antigemination (in the form of a NoGEM-type constraint) and assimilation (in the form of an AGREE-type constraint). The facts of Polish discussed in this paper reveal that much more follows from this analysis than the explanation of the featural content of 'sufficient similarity', the main focus of Baković (2005); three other facts about Polish are also predicted by the analysis. The first is the fact that antigemination via epenthesis is restricted to potential non-vowel-adjacent geminates in Polish, and thus so is the avoidance via epenthesis of 'sufficiently similar' adjacent consonants. The second is the fact that CPA is optional in Polish, and thus so is epenthesis in those non-vowel-adjacent contexts where CPA is otherwise expected to apply to create a geminate. The third is the fact that application of CPA appears to be on the decline in Polish, and thus so does application of epenthesis appear to be (in those contexts where it is optional).

An alternative analysis of these data in which 'sufficient similarity' is independently built in to the definition of the epenthesis process fails to explain these three facts, even putting aside the necessarily accidental coincidence between the content of 'sufficient similarity' (= ignoring differences in voicing and subcoronal place) and the processes of assimilation for which there is independent evidence. At best, this alternative could account for the first fact: because a single epenthesis process is responsible for identical and 'sufficiently similar' adjacent consonant avoidance-in relevant respects equivalent to the rule in (6) - then of course the non-vowel-adjacent condition on the former is a condition on the latter. The second and third facts remain beyond the grasp of this alternative, however, simply because there is no way to connect the optionality of epenthesis to the optionality of CPA. Indeed, the fact that epenthesis is optional in some contexts and obligatory in others effectively requires splitting it into two separate processesjeopardizing the account of the first fact, because now it is an accident that both of these processes happen to apply only in non-vowel-adjacent contexts. 
The success of our formal analysis over this kind of alternative does not mean that our work on the phonology of monoconsonantal proclitics is done. There are several issues raised by these facts that were not our focus here but that we discuss elsewhere or hope to illuminate in future research. Foremost among these issues are the independent motivation for contextual constraints on geminates discussed in Sect. 2.2 (on which see Pająk 2009a, 2009b) and the role of other factors affecting stochastic activity discussed in Sect. 4.4. Nevertheless, we hope to have made contributions to better understandings of Polish phonology, phonological theory, and phonological variation.

The formal link between the optionality of CPA and the optionality of epenthesisthat is, the proposed explanation of the second and third facts-is perhaps the most significant result of this article. There are many factors that have long been known to affect the variability of optional processes, but to the best of our knowledge the formal properties of other processes are not among these better-understood factors. We hope that the present work will lead to the identification and careful study of more examples of this kind.

An intriguing case appears to be found in Classical Mandaic (Malone 1967, 1973). The main interaction in this case is again between assimilation and epenthesis. The conditions for epenthesis and thereby its interaction with assimilation differ from those in Polish in noteworthy ways, but the basic pattern of interaction remains essentially the same. The relevant epenthesis process applies to avoid triconsonantal clusters, not geminates $(/ \mathrm{krxa} \theta / \rightarrow$ [kerxa $\theta]$ 'she turned around'); indeed, geminates and other 'ligatured clusters' block the application of this epenthesis process (/maxrxi $\widehat{\theta} / \rightarrow$ [maxroxe $\theta$ ], *[maxerxe $\theta$ ] 'thou wrappest'). The assimilation process involves the reflexive prefix $/ \theta /$, which totally assimilates to a following consonant, but only optionally (/i $\theta$ karraxyu $\mathrm{n} / \rightarrow$ [ekkarraxyon] $\sim$ [e $\theta$ karraxyon] 'stand ye around'). In triconsonantal clusters, epenthesis applies only if assimilation (and ultimately degemination and spirantization) has not (/i $\theta \mathrm{krik} / \rightarrow$ [e $\theta$ exrex] $\sim$ [exrex] 'he was converted'). So, while the conditions on epenthesis in Polish depend on the result of applying CPA, the conditions on epenthesis in Classical Mandaic depend on the result of not applying the relevant assimilation process.

This all-too-brief summary of the relevant facts of Classical Mandaic is insufficient to draw any large conclusions, and the fact that the language is no longer spoken obviously limits our ability to pursue it as deeply as we have for Polish here. But the existing description of this case gives us some assurance that other cases can be found if we look for them.

Acknowledgements We would like to thank the following people who contributed valuable comments and suggestions at different stages of this project: Adam Albright, Amalia Arvaniti, Klinton Bicknell, Lucien Carroll, Rebecca Colavin, Josef Fruehwald, Diamandis Gafos, Alex del Giudice, Matt Goldrick, Cynthia Kilpatrick, Bill Labov, Géraldine Legendre, Mark Liberman, J. Grant Loomis, John McCarthy, Joe Pater, Jason Riggle, Hannah Rohde, Sharon Rose, Paul Smolensky, Colin Wilson, as well as audiences at WECOL 2007, the $82^{\text {nd }}$ Annual Meeting of the LSA, UC San Diego, the University of Pennsylvania, Johns Hopkins University, and New York University. We are especially grateful to Michael Kenstowicz and three anonymous reviewers whose comments led to vast improvements in the paper. All remaining errors are ours.

Open Access This article is distributed under the terms of the Creative Commons Attribution Noncommercial License which permits any noncommercial use, distribution, and reproduction in any medium, provided the original author(s) and source are credited. 


\section{Appendix}

This section provides a complete description of the phonetic study discussed in Sects. 3.3 and 4.3 , together with the results split by item.

\section{A.1 Method}

\section{A.1.1 Participants}

Twenty-one native speakers of Polish (ten males and eleven females) participated in the experiment. They belonged to either a younger age group (average age: 27, ranging from 24 to 31) or an older age group (average age: 54, ranging from 43 to 61). They were recruited by word of mouth and volunteered for the experiment without monetary compensation. All of them lived in Kraków, Poland, and-with the exception of one person who was born and raised in Warsaw-they all grew up in the southern region of Poland, near Kraków. They reported no history of speech or hearing disorders.

\section{A.1.2 Design and procedure}

The design of the experiment was intended to elicit speech that was as spontaneous as possible, but at the same time assuring that the target sequences of sounds were produced. Thus, care was taken to maintain a certain resemblance to a real conversation, which nevertheless had to be restricted in order to elicit the target expressions.

The experiment took place in Kraków, Poland. The participants were seated in a quiet room in front of the experimenter (the first author of the paper, a native speaker of Polish). Immediately prior to beginning the experiment, they were engaged in a short, casual conversation with the experimenter in order to decrease the anxiety related to participating in an experiment and to establish a comfortable interaction with the experimenter. Subsequently, the procedure of the experiment was explained. The participants were instructed that they would listen to a fictitious story over headphones. The story would be stopped every few sentences, and during the pause the experimenter would ask them questions about the story content. This was done to ensure that the participants focused on the content of their speech rather than on the pronunciation. The participants were asked to use casual, everyday speech. Furthermore, they were told to respond in full sentences and repeat the response twice. Both repetitions were used for analysis. In cases when the participants did not know the answer, the relevant story fragment was replayed to them, and, subsequently, the question was repeated. The total duration of the experiment was about 20 minutes.

\section{A.1.3 Materials}

The materials consisted of a ficticious story written in Polish by the experimenter. The story was written in a simple language to encourage casual speech reponses. An example of a story fragment and a corresponding question (translated into English) are provided in (1). 
(1) Example of a story fragment, a question, and an expected answer

Story fragment: "The wizard began preparing a magic potion, which was supposed to help us in our mission. He put a large pot on the fire and carefully chose the herbs for the potion."

Question: "What was the magic potion made of?"

Expected answer: "The magic potion was made of herbs."

There was a total of 53 questions for the story. 24 of them elicited responses that included sequences of the clitic /z/ with stems beginning with alveolo-palatal and postalveolar stridents ('target words'), and 29 of them served as fillers and included either different clitics or no clitics at all. Note that neither the story nor the questions included the target sequences so that the participants would not be biased by the forms that they heard. Rather, the questions were formulated in such a way that the participants had to paraphrase what they heard in the story by using the clitic /z/ with a target word.

Care was taken to use fairly frequent target words (one nonce word had to nevertheless be used due to the nonexistence of any word with one of the desired types of initial cluster). The target expressions are listed in (2), divided by the type of possible outputs: $\mathrm{CPA} \sim$ no CPA and epenthesis $\sim$ no epenthesis.

(2) Target expressions

\begin{tabular}{|c|c|c|}
\hline \multicolumn{2}{|c|}{$\mathrm{CPA} \sim \mathrm{No} \mathrm{CPA}$} & \multirow{2}{*}{$\begin{array}{l}\text { EPENTHESIS } \sim \\
\text { NO EPENTHESIS }\end{array}$} \\
\hline fricative-initial stems & affricate-initial stems & \\
\hline $\begin{array}{l}/ z /+z \varepsilon m^{j} \text { anki 'from a } \\
\text { dugout' }\end{array}$ & $\begin{array}{l}\text { /z/+ đłzupli 'from a tree } \\
\text { hole' }\end{array}$ & $\begin{array}{l}/ \mathrm{z} /+\operatorname{zrcbak}^{\mathrm{j}} \varepsilon \mathrm{cm} \text { 'with a } \\
\text { colt' }\end{array}$ \\
\hline /z/+zuw 'from herbs' & $|z|+\widehat{d}$ zqvigu 'from a crane' & $|z|+z$ rudwa 'from a spring' \\
\hline $\begin{array}{l}\text { /z/+zqgglazem 'with a } \\
\text { sailor' }\end{array}$ & $\begin{array}{l}\text { /z/+Ĉdzungli 'from a } \\
\text { jungle' }\end{array}$ & /z/+zmijõ 'with a viper’ \\
\hline /z/+zilletki 'from a razor' & $\begin{array}{l}\mid \mathrm{z} /+\widehat{\mathrm{dz}}_{\mathrm{z} m a k}{ }^{\mathrm{j}} \varepsilon \mathrm{m} \text { ' with a } \\
\text { [nonce word]' }\end{array}$ & /z/+zviru 'from gravel' \\
\hline /z/+cana 'from hay' & 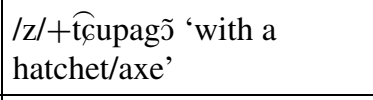 & $\begin{array}{l}\text { /z/+6rubokrẽtem 'with a } \\
\text { screwdriver' }\end{array}$ \\
\hline$/ z /+6 \varepsilon \mathrm{k}^{\mathrm{j}} \varepsilon \mathrm{r} \tilde{\rho}$ 'with an axe' & $\mid z /+\overparen{t_{6}} m \tilde{~}$ 'with a moth' & $\begin{array}{l}\text { /z/+6f' } \mathrm{j}^{\mathrm{j}} \text { ôtini 'from a } \\
\text { temple' }\end{array}$ \\
\hline /z/+sabli 'from a saber' & $\begin{array}{l}\text { Iz/+țarod } \\
\text { wizard' }\end{array}$ & /z/+şlaxtõ 'with nobility' \\
\hline $\begin{array}{l}\text { /z/+soferem 'with a } \\
\text { chauffeur' }\end{array}$ & /z/+ț̂skafkõ 'with hiccups' & 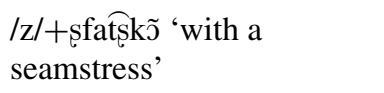 \\
\hline
\end{tabular}

The story was prepared in two versions, which differed in the order of presentation of the target words (minor differences in content were also inevitable in order to maintain coherence within the two versions). Half of the participants in each age group were presented with version 1 of the story, and the other half with version 2. Additionally, in order to control for a potential bias in applying CPA because it might have been heard in 
the story itself (in non-tested expressions), the two versions of the story were recorded in two additional conditions: one in which CPA was always applied (where applicable), and another in which CPA was never applied. (The same pattern was maintained for the experimenter's questions after the story.) Half of the participants heard the 'CPA' version, while the other half heard the 'no CPA' version.

The four versions of the story were recorded by the experimenter in a quiet room using a Marantz PMD660 digital recorder and an Audio-Technica 831b clip-on microphone (frequency response of $40-18,000 \mathrm{~Hz}$ ). The speech was casual and relatively fast in order to introduce a certain amount of difficulty to the task. The sound files were cut into fragments after which the questions about the story content were supposed to be asked. For the experiment, the files were concatenated using the 'concatenate recoverably' function in the Praat speech analysis software (Boersma and Weenink 2008). This function created a TextGrid associated with the sound file, where each of the fragments was labeled. During the experiment, the experimenter played each sound fragment using the TextGrid of the concatenated file in Praat. The total duration of the story (without breaks) was about 5 minutes.

\section{A.1.4 Recordings and acoustic measurements}

The participants' speech was recorded digitally at $48 \mathrm{kHz}$ sampling rate (16 bit resolution) using a Marantz PMD660 digital recorder and an Audio-Technica 831b clip-on microphone (frequency response of 40-18,000 Hz). The recordings were annotated and analyzed using Praat. For each target expression, the durations of the following were annotated using TextGrids: the clitic / $\mathrm{z} /$, the stem-initial consonant of the target word, and-where applicable - the epenthetic vowel. The onset and offset of stridents were marked according to the presence of high amplitude aperiodic noise. The vowel boundaries were determined by the presence of a periodic wave and regular formants.

The presence or absence of CPA was determined by comparing the spectral properties of the clitic to the properties of the following consonant, separately for each token. This was done by calculating the center of gravity $(\mathrm{CoG})$ for each target consonant at three points: at one-quarter, at half, and at three-quarters of its total duration (see e.g. Jassem 1995 for this type of analysis of Polish fricatives). Voiced fricatives were first high-pass filtered at $500 \mathrm{~Hz}$ to avoid the results being skewed by F0. The three measurements were averaged, and a difference in mean $\mathrm{CoG}$ between /z/ and the following consonant was calculated for each test token. A low difference in mean $\mathrm{CoG}$ was assumed to indicate a high degree of assimilation, and conversely, a high difference in mean CoG was assumed to indicate a low degree of assimilation. The measurements were log-transformed for the purposes of statistical analysis.

The presence or absence of vowel epenthesis was determined by the presence/absence of a periodic wave and regular formants between the clitic and the stem.

\section{A.2 Results}

For the purposes of illustrating the approximate rates of CPA, the data were divided by assuming that assimilation had applied when the difference in mean CoG between the clitic /z/ and the following consonant was below $1,000 \mathrm{~Hz}$, and that assimilation had not applied when the difference in mean CoG was at least $1,000 \mathrm{~Hz}$. This is shown separately for fricative-initial stems in (3) and for affricate-initial stems in (4). Furthermore, in order to provide a clearer picture of the degree of assimilation, both tables include percentages 
of what we assume to be full assimilation (f), with a difference in mean CoG below $500 \mathrm{~Hz}$, and of what we assume to be complete lack of assimilation (1), with a difference in mean $\mathrm{CoG}$ of at least $1,500 \mathrm{~Hz}$.

Finally, the table in (5) provides the results of epenthesis rates.

(3) Rates of CPA: fricative-initial stems

\begin{tabular}{|c|c|c|c|}
\hline \multirow{2}{*}{\multicolumn{2}{|c|}{ INPUT }} & \multicolumn{2}{|c|}{ OUTPUT } \\
\hline & & CPA & NO CPA \\
\hline \multirow[t]{2}{*}{ a. } & $/ z /+z \varepsilon m^{j}$ anki 'from a dugout' & $\begin{array}{c}50.00 \% \\
\text { (f-28.57\%) }\end{array}$ & $\begin{array}{c}50.00 \% \\
(1-42.86 \%)\end{array}$ \\
\hline & & $\mathrm{O}-41.67 \% \quad \mathrm{Y}-53.33 \% *$ & O-58.33\% Y-46.67\% \\
\hline \multirow[t]{2}{*}{ b. } & \multirow[t]{2}{*}{ /z/+zuw 'from herbs' } & $\begin{array}{c}69.05 \% \\
(\mathrm{f}-45.24 \%)\end{array}$ & $\begin{array}{c}30.95 \% \\
(1-19.05 \%)\end{array}$ \\
\hline & & O-66.67\% Y-70.00\% & $\mathrm{O}-33.33 \% \quad \mathrm{Y}-30.00 \%$ \\
\hline \multirow[t]{2}{*}{ c. } & \multirow[t]{2}{*}{ /z/+z̨eglazem 'with a sailor' } & $\begin{array}{c}11.90 \% \\
(\mathrm{f}-2.38 \%)\end{array}$ & $\begin{array}{c}88.10 \% \\
(1-59.52 \%)\end{array}$ \\
\hline & & O-25.00\% Y-6.67\% & O-75.00\% Y-93.33\% \\
\hline \multirow[t]{2}{*}{ d. } & \multirow[t]{2}{*}{ /z/+zilletki 'from a razor' } & $\begin{array}{c}50.00 \% \\
(\mathrm{f}-23.81 \%)\end{array}$ & $\begin{array}{c}50.00 \% \\
(1-35.71 \%)\end{array}$ \\
\hline & & O-50.00\% Y-50.00\% & O-50.00\% Y-50.00\% \\
\hline \multirow[t]{2}{*}{ e. } & \multirow[t]{2}{*}{ /z/+cana 'from hay' } & $\begin{array}{c}38.10 \% \\
(\mathrm{f}-14.29 \%)\end{array}$ & $\begin{array}{c}61.90 \% \\
(1-38.10 \%)\end{array}$ \\
\hline & & $0-66.67 \% \quad Y-26.67 \%$ & O-33.33\% Y-73.33\% \\
\hline \multirow[t]{2}{*}{ f. } & \multirow[t]{2}{*}{$/ \mathrm{z} /+6 \varepsilon \mathrm{k}^{\mathrm{j}} \varepsilon \mathrm{r} \tilde{\partial}$ 'with an axe' } & $\begin{array}{c}54.76 \% \\
(\mathrm{f}-26.19 \%)\end{array}$ & $\begin{array}{c}45.24 \% \\
(1-21.43 \%)\end{array}$ \\
\hline & & O-75.00\% Y-26.67\% & $\mathrm{O}-25.00 \% \quad \mathrm{Y}-73.33 \%$ \\
\hline \multirow[t]{2}{*}{ g. } & \multirow[t]{2}{*}{ /z/+sabli 'from a saber' } & $\begin{array}{c}45.24 \% \\
(\mathrm{f}-19.05 \%)\end{array}$ & $\begin{array}{c}54.76 \% \\
(1-33.33 \%)\end{array}$ \\
\hline & & O-33.33\% Y-50.00\% & O-66.67\% Y-50.00\% \\
\hline \multirow[t]{2}{*}{ h. } & \multirow[t]{2}{*}{ |z/+şferem 'with a chauffeur' } & $\begin{array}{c}57.14 \% \\
(\mathrm{f}-30.95 \%)\end{array}$ & $\begin{array}{c}42.86 \% \\
(1-16.67 \%)\end{array}$ \\
\hline & & O-50.00\% Y-60.00\% & $\mathrm{O}-50.00 \% \quad \mathrm{Y}-40.00 \%$ \\
\hline \multirow{2}{*}{\multicolumn{2}{|c|}{$\begin{array}{l}\text { TOTAL AVERAGE } \\
N=336\end{array}$}} & $\begin{array}{c}47 \% \\
(\mathrm{f}-24 \%)\end{array}$ & $\begin{array}{c}53 \% \\
(1-33 \%)\end{array}$ \\
\hline & & $0-51 \% \quad Y-45 \%$ & $0-49 \% \quad \mathrm{Y}-55 \%$ \\
\hline
\end{tabular}

$* \mathrm{O}(n=6)$-older group of subjects (average age: 54, ranging from 43 to 61 )

$\mathrm{Y}(n=15)$ - younger group of subjects (average age 27, ranging from 24 to 31 )

$\mathrm{f}$-full assimilation (difference in mean CoG: below $500 \mathrm{~Hz}$ )

1 - complete lack of assimilation (difference in mean CoG: at least $1,500 \mathrm{~Hz}$ ) 
(4) Rates of CPA: affricate-initial stems

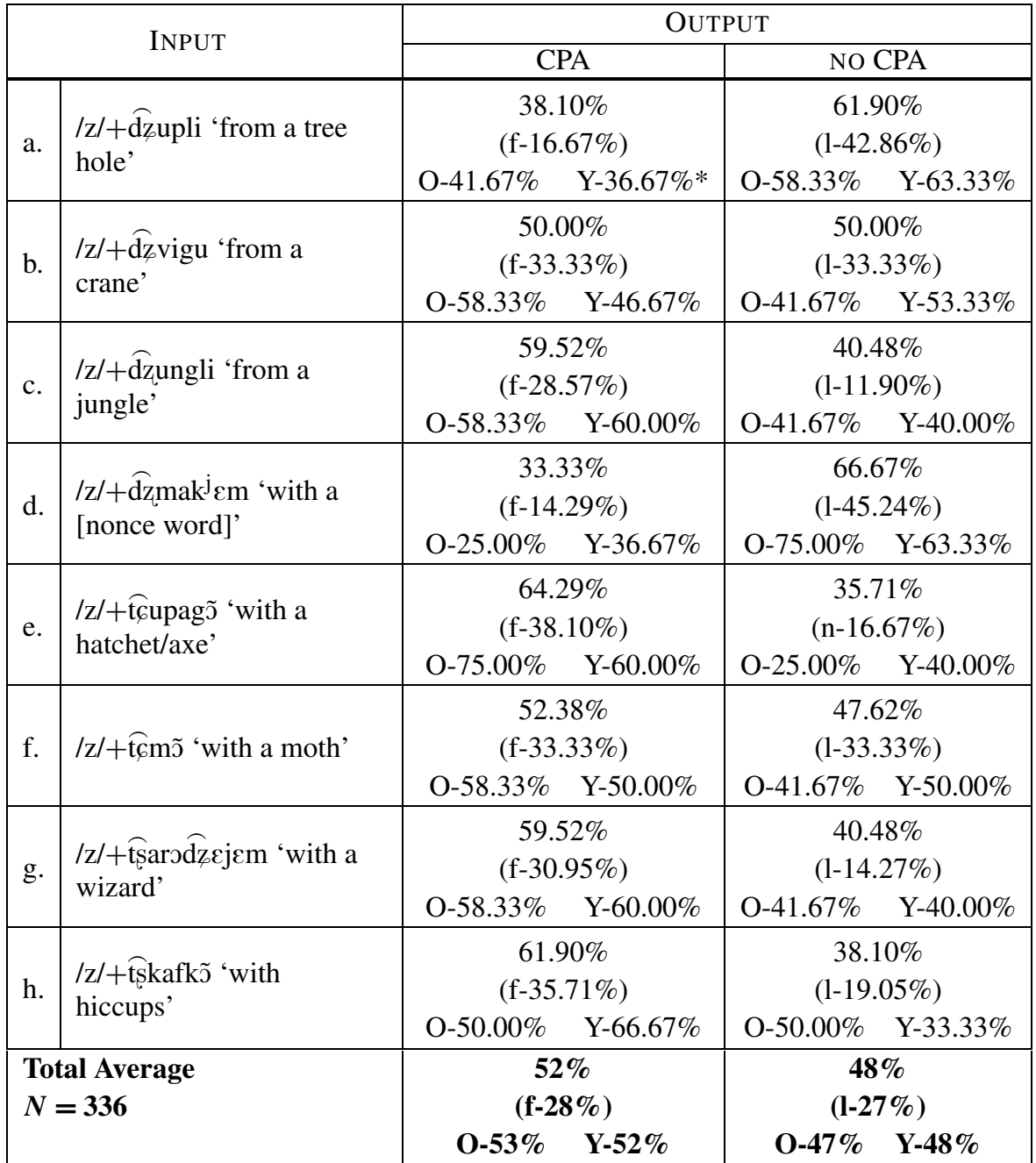

$* \mathrm{O}(n=6)$-older group of subjects (average age: 54, ranging from 43 to 61 )

$\mathrm{Y}(n=15)$-younger group of subjects (average age 27, ranging from 24 to 31)

$\mathrm{f}$-full assimilation (difference in mean CoG: below $500 \mathrm{~Hz}$ )

1 - complete lack of assimilation (difference in mean CoG: at least 1,500 Hz) 
(5) Rates of epenthesis

\begin{tabular}{|c|c|c|c|}
\hline \multirow{2}{*}{\multicolumn{2}{|c|}{ INPUT }} & \multicolumn{2}{|c|}{ OUTPUT } \\
\hline & & EPENTHESIS & \begin{tabular}{|l|} 
NO EPENTHESIS \\
\end{tabular} \\
\hline \multirow{2}{*}{ a. } & \multirow{2}{*}{$\mid z /+z \operatorname{rcbak}^{j} \varepsilon m$ 'with a colt' } & $92.86 \%$ & $7.14 \%$ \\
\hline & & O-100\% Y-90.00\%* & O- $0.00 \% \quad \mathrm{Y}-10.00 \%$ \\
\hline \multirow{2}{*}{ b. } & \multirow{2}{*}{$\mid z /+z$ rudwa 'from a spring' } & $85.71 \%$ & $14.29 \%$ \\
\hline & & O-100\% Y-80.00\% & O- $0.00 \% \quad$ Y-20.00\% \\
\hline \multirow{2}{*}{ c. } & \multirow{2}{*}{ /z/+zmijõ 'with a viper' } & $85.71 \%$ & $14.29 \%$ \\
\hline & & O-83.33\% Y-86.67\% & O-16.67\% Y-13.33\% \\
\hline \multirow{2}{*}{ d. } & \multirow{2}{*}{ /z/+ziviru 'from gravel' } & $80.95 \%$ & $19.05 \%$ \\
\hline & & O-100\% Y-73.33\% & O- $0.00 \% \quad \mathrm{Y}-26.67 \%$ \\
\hline \multirow{2}{*}{ e. } & \multirow{2}{*}{$\begin{array}{l}\text { /z/+ crubokrẽtem 'with a } \\
\text { screwdriver' }\end{array}$} & $73.81 \%$ & $26.19 \%$ \\
\hline & & O-83.33\% Y-70.00\% & O- $16.67 \% \quad \mathrm{Y}-30.00 \%$ \\
\hline \multirow{2}{*}{ f. } & \multirow{2}{*}{$\mid z /+{ }_{6} f$ ว̃̃tini 'from a temple' } & $90.48 \%$ & $9.52 \%$ \\
\hline & & O-100\% Y-86.67\% & $\mathrm{O}-0.00 \% \quad \mathrm{Y}-13.33 \%$ \\
\hline \multirow{2}{*}{ g. } & \multirow{2}{*}{ /z/+slaxtõ 'with nobility' } & $80.95 \%$ & $19.05 \%$ \\
\hline & & O-100\% Y-73.33\% & O- $0.00 \% \quad \mathrm{Y}-26.67 \%$ \\
\hline \multirow{2}{*}{ h. } & \multirow{2}{*}{ /z/+sfatşs $\tilde{x}$ 'with a seamstress' } & $69.05 \%$ & $30.95 \%$ \\
\hline & & O-66.67\% Y-70.00\% & O-33.33\% Y-70.00\% \\
\hline \multirow{2}{*}{\multicolumn{2}{|c|}{$\begin{array}{l}\text { Total Average } \\
N=336\end{array}$}} & \multirow{2}{*}{\begin{tabular}{cc}
\multicolumn{2}{c}{$82 \%$} \\
$0.92 \%$ & Y-79\%
\end{tabular}} & $18 \%$ \\
\hline & & & O-8\% Y-21\% \\
\hline
\end{tabular}

$* \mathrm{O}(n=6)$-older group of subjects (average age: 54, ranging from 43 to 61)

$\mathrm{Y}(n=15)$-younger group of subjects (average age 27, ranging from 24 to 31 )

\section{References}

ROA = Rutgers Optimality Archive. http://roa.rutgers.edu/.

Baković, Eric. 2005. Antigemination assimilation and the determination of identity. Phonology 22: 279315.

Baković, Eric. 2007. A revised typology of opaque generalisations. Phonology 24: 217-259 [ROA-850].

Becker, Michael. 2009. Phonological trends in the lexicon: the role of constraints. PhD dissertation, University of Massachusetts, Amherst.

Becker, Michael, and Lena Fainleib. 2009. Surface-based generalizations over lexical exceptions. Paper presented at the 83rd LSA annual meeting, in San Francisco.

Beckman, Jill. 1998. Positional faithfulness. PhD dissertation, University of Massachusetts, Amherst.

Bethin, Christina Y. 1992. Polish syllables. The role of prosody in phonology and morphology. Columbus: Slavica.

Blust, Robert. 1995. Austronesian comparative dictionary. Honolulu: University of Hawaii at Manoa.

Blust, Robert. 2001. Language, dialect, and riotous sound change: the case of Sa'ban. In Papers from the 9th annual meeting of the Southeast Asian Linguistics Society, 1999, ed. G. Thurgood, 249-359. Tempe: Arizona State University Monograph Series Press.

Blust, Robert. 2007. Disyllabic attractors and anti-antigemination in Austronesian sound change. Phonology 24: 1-36.

Boersma, Paul. 1998. Functional Phonology: Formalizing the interactions between articulatory and perceptual drives. PhD dissertation, University of Amsterdam.

Boersma, Paul, and Bruce Hayes. 2001. Empirical tests of the Gradual Learning Algorithm. Linguistic Inquiry 32: 45-86 [ROA-348]. 
Boersma, Paul, and David Weenink. 2008. Praat: doing phonetics by computer (Version 5.0.22). [Computer program].

Casali, Roderic F. 1997. Vowel elision in hiatus contexts: which vowel goes? Language 73: $493-533$.

Ćavar, Małgorzata E. 2004. Palatalization in Polish. An interaction of articulatory and perceptual factors. $\mathrm{PhD}$ dissertation, University of Potsdam.

Coetzee, Andries W. 2009a. Learning lexical indexation. Phonology 26: 109-145.

Coetzee, Andries W. 2009b. Phonological variation and lexical frequency. In Vol. 1 of Proceedings of NELS 38, eds. Anisa Schardl, Martin Walkow, and Muhammad Abdurrahman, 189-202. Amherst: GLSA [ROA-952].

Coetzee, Andries W., and Joe Pater. 2008a. Weighted constraints and gradient Restrictions on place cooccurrence in Muna and Arabic. Natural Language \& Linguistic Theory 26: 289-337.

Coetzee, Andries W., and Joe Pater. 2008b. The place of variation in phonological theory. Manuscript, University of Michigan and University of Massachusetts [ROA 946].

Czaykowska-Higgins, Ewa. 1988. Investigations into Polish morphology and phonology. PhD dissertation, Massachusetts Institute of Technology.

Dmitrieva, Olga. 2009. Geminate typology and perception of consonant length. Experimental evidence from Russian. Paper presented at the 83rd LSA annual meeting, in San Francisco.

Dunaj, Boguslaw. 1985. Grupy spółgłoskowe współczesnej polszczyzny mówionej (w języku mieszkańców Krakowa). Zeszyty Naukowe Uniwersytetu Jagiellońskiego: Prace Językoznawcze 83.

Gussmann, Edmund. 1980. Studies in abstract phonology. Cambridge/London: MIT Press.

Gussmann, Edmund. 2007. The phonology of Polish. Oxford: Oxford University Press.

Hamann, Silke. 2004. Retroflex fricatives in Slavic languages. Journal of the IPA 34: 53-67.

Ito, Junko, and Armin Mester. 1999. The structure of the phonological lexicon. In The handbook of Japanese linguistics, ed. Tsujimura Natsuko, 62-100. Malden: Blackwell.

Jassem, Wiktor. 1995. The acoustic parameters of Polish voiceless fricatives: an analysis of variance. Phonetica 52: 251-258.

Kawahara, Shigeto. 2005. Voicing and geminacy in Japanese: an acoustic and perceptual study. University of Massachusetts Occasional Papers in Linguistics 31: 87-120.

Keating, Patricia A. 1991. Coronal places of articulation. In Phonetics and phonology. The special status of coronals: internal and external evidence, eds. Carole Paradis and Jean-François Prunet, 29-48. San Diego: Academic Press.

Kenstowicz, Michael. 2005. The phonetics and phonology of Korean loanword adaptation. In Proceedings of the first European conference on Korean linguistics, ed. Sang-Jik Rhee, 17-32. Seoul: Hankook.

Kisseberth, Charles W. 1970. On the functional motivation of phonological rules. Linguistic Inquiry 1: 291-306.

Kurisu, Kazutaka. 2001. The phonology of morpheme realization. PhD dissertation, University of California, Santa Cruz.

Ladefoged, Peter, and Ian Maddieson. 1996. The sounds of the world's languages. Oxford, Cambridge: Blackwell.

Laskowski, Roman. 1975. Studia nad morfonologiq wspótczesnego jezyka polskiego. Wrocław: Zakład Narodowy im. Ossolińskich.

Lombardi, Linda. 1999. Positional faithfulness and voicing assimilation in Optimality Theory. Natural Language \& Linguistic Theory 17: 267-302.

Malone, Joseph L. 1967. A morphologic grammar of the classical mandaic verb. PhD dissertation, University of California, Berkeley.

Malone, Joseph L. 1973. A case of optional-obligatory rule ordering. Foundations of Language 10: 579580.

Markowski, Andrzej (ed.). 1999. Nowy słownik poprawnej polszczyzny. Warszawa: PWN.

McCarthy, John, and Alan Prince. 1995. Faithfulness and reduplicative identity. In University of Massachusetts occasional papers in linguistics 18: papers in optimality theory, eds. Jill Beckman, Suzanne Urbanczyk, and Laura Walsh Dickey, 249-384. Amherst: GLSA [ROA-60].

McCrary, Kristie. 2004. Reassessing the role of the syllable in Italian phonology: an experimental study of consonant cluster syllabification, definite article allomorphy and segment duration. PhD dissertation, University of California, Los Angeles.

Müller, Gereon. 1999. Optionality in optimality-theoretic syntax. Glot International 4(5): 3-8.

Muller, Jennifer. 1999. A unified mora account of Chuukese. Proceedings of WCCFL 18: 393-405.

Muller, Jennifer. 2001. The phonology and phonetics of word-initial geminates. $\mathrm{PhD}$ dissertation, Ohio State University. 
Osowicka-Kondratowicz, Magdalena. 2004. Asymilacje spółgłosek zębowych i dziąsłowych do palatalnych w pozycji przed palatalnymi. Prace Jezykoznawcze 4: 1-17. Uniwersytet Warmińsko-Mazurski w Olsztynie.

Osowicka-Kondratowicz, Magdalena. 2005. Assimilative palatalization within consonantal clusters in Polish. Studia Phonetica Posnaniensia 7: 5-22.

Pająk, Bożena. 2009a. Context-dependent perception of geminates. Poster presented at the 83rd LSA annual meeting, in San Francisco.

Pająk, Bożena. 2009b. Contextual constraints on geminates: the case of Polish. Paper presented at the 35th BLS annual meeting, in Berkeley (to appear in proceedings).

Pater, Joe. 1999. Austronesian nasal substitution and other NC effects. In The prosody morphology interface, eds. René Kager, Harry van der Hulst, and Wim Zonneveld, 310-343. Cambridge: Cambridge University Press.

Pater, Joe. 2000. Non-uniformity in English secondary stress: the role of ranked and lexically specific constraints. Phonology 17: 237-274.

Pater, Joe. 2006. The locus of exceptionality: Morpheme-specific phonology as constraint indexation. In UMOP: papers in optimality theory III, eds. Leah Bateman and Adam Werle, 1-36. Amherst: GLSA.

Pater, Joe. 2008. Morpheme-specific phonology: constraint indexation and inconsistency resolution. In Phonological argumentation: essays on evidence and motivation, ed. S. Parker, 1-33. London: Equinox.

Pater, Joe, and Andries W. Coetzee. 2005. Lexically specific constraints: gradience, learnability, and perception. In Proceedings of the Korea international conference on phonology, 85-119. Seoul: The Phonology-Morphology Circle of Korea.

Podesva, Robert J. 2002. Segmental constraints on geminates and their implications for typology. Paper presented at the 76th LSA annual meeting, in San Francisco.

Prince, Alan. 1998. Two lectures on optimality theory, lecture 2: current directions in optimality theory. Talk given at the 1998 Phonology Forum, Kobe (http://equinox.rutgers.edu/gamma/kobe-all.pdf).

Prince, Alan, and Paul Smolensky. 1993/2004. Optimality theory: constraint interaction in generative grammar. Oxford: Blackwell [ROA-537].

Rochoń, Marzena. 2000. Prosodic constituents in the representation of consonantal sequences in Polish. ZAS Papers in Linguistics 19: 177-205.

Rose, Sharon. 2000. Rethinking geminates, long-distance geminates, and the OCP. Linguistic Inquiry 31: 85-122.

Rowicka, Grażyna. 1994. Polish palatal assimilation in prefixed words. In Linguistics in the Netherlands, eds. Reineke Bok-Bennema and Crit Cremers, 211-222. Amsterdam: Benjamins.

Rubach, Jerzy. 1977. Changes of consonants in English and Polish. A generative account. Wrocław: Zakład Narodowy im. Ossolińskich.

Rubach, Jerzy. 1984. Cyclic and lexical phonology. The structure of Polish. Dordrecht, Cinnaminson: Foris.

Rubach, Jerzy. 1985. Lexical phonology: lexical and postlexical derivations. Phonology Yearbook 2: 157172.

Rubach, Jerzy. 1986. Does the obligatory contour principle operate in Polish? Studies in the Linguistic Sciences 16: 133-147.

Rubach, Jerzy. 1994. Affricates as strident stops in Polish. Linguistic Inquiry 25(1): 119-143.

Rubach, Jerzy. 2008. Prevocalic faithfulness. Phonology 25(3): 433-468.

Rubach, Jerzy, and Geert E. Booij. 1990. Edge of constituent effects in Polish. Natural Language \& Linguistic Theory 8(3): 427-463.

Rubach, Jerzy, and Geert E. Booij. 2001. Allomorphy in optimality theory: Polish iotation. Language 77: 26-60.

Sawicka, Irena. 1995. Fonologia. In Gramatyka wspótczesnego języka polskiego. Fonetyka i fonologia, ed. Henryka Wróbel, 105-195. Kraków: Instytut Języka Polskiego PAN.

Steele, Richard. 1973. The segmental phonology of Contemporary Standard Polish. PhD dissertation, Harvard University.

Szpyra, Jolanta. 1992. The phonology of Polish prefixation. In Phonological investigations, eds. Jacek Fisiak and Stanisław Puppel, 185-218. Amsterdam/Philadelphia: Benjamins.

Thurgood, Ela. 2002. The recognition of geminates in ambiguous contexts in Polish. Speech Prosody 2002: $659-662$.

Thurgood, Graham. 1993. Geminates: a cross-linguistic examination. In Papers in honor of Frederick $H$. Brengelman on the occasion of the twenty-fifth anniversary of the Department of Linguistics, CSU 
Fresno, eds. Joel Ashmore Nevis, Gerald McMenamin and Graham Thurgood, 129-139. Fresno: Department of Linguistics, California State University.

Van den Berg, René. 1989. A grammar of the Muna language. Dordrecht: Foris.

Zajda, Aleksander. 1977. Some problems of Polish pronunciation in the dictionary of Polish pronunciation. In Słownik wymowy polskiej/the dictionary of Polish pronunciation, eds. Mieczysław Karaś and Maria Madejowa, L-LXII. Warszawa: Państwowe Wydawnictwo Naukowe. 